\title{
Photocatalytic Activity of Silver-Based Biomimetics Composites
}

\author{
Abniel Machín 1,*(D), Loraine Soto-Vázquez ${ }^{2}$, Carla Colón-Cruz ${ }^{3}$, Carlos A. Valentín-Cruz ${ }^{3}$, \\ Gerardo J. Claudio-Serrano $^{3}$, Kenneth Fontánez ${ }^{4}$, Edgard Resto ${ }^{2}$, Florian I. Petrescu ${ }^{5}$, Carmen Morant ${ }^{6}$ (D) \\ and Francisco Márquez ${ }^{3, * \mathbb{D}}$
}

1 Arecibo Observatory, Universidad Ana G. Méndez-Cupey Campus, San Juan 00926, Puerto Rico

2 Materials Characterization Center, Molecular Sciences Research Center, University of Puerto Rico, San Juan 00926, Puerto Rico; lorainesoto@gmail.com (L.S.-V.); edgard.resto@upr.edu (E.R.)

3 Nanomaterials Research Group, School of Natural Sciences and Technology, Universidad Ana G. Méndez-Gurabo Campus, Gurabo 00778, Puerto Rico; ccolon265@email.uagm.edu (C.C.-C.); cvalentin51@email.uagm.edu (C.A.V.-C.); gclaudio17@email.uagm.edu (G.J.C.-S.)

4 Department of Chemistry, University of Puerto Rico-Río Piedras, San Juan 00925, Puerto Rico; kenneth.fontanez@gmail.com

5 IFToMM-ARoTMM, Bucharest Polytechnic University, 060042 Bucharest, Romania; fitpetrescu@gmail.com

6 Department of Applied Physics, Autonomous University of Madrid and Instituto de Ciencia de Materiales Nicolas Cabrera, 28049 Madrid, Spain; c.morant@uam.es

* Correspondence: machina1@uagm.edu (A.M.); fmarquez@uagm.edu (F.M.)

check for updates

Citation: Machín, A.; Soto-Vázquez, L.; Colón-Cruz, C.; Valentín-Cruz,

C.A.; Claudio-Serrano, G.J.; Fontánez, K.; Resto, E.; Petrescu, F.I.; Morant, C.; Márquez, F.; et al. Photocatalytic Activity of Silver-Based Biomimetics Composites. Biomimetics 2021, 6, 4. https://doi.org/10.3390/biomimetics 6010004

Received: 14 October 2020 Accepted: 30 December 2020 Published: 4 January 2021

Publisher's Note: MDPI stays neutral with regard to jurisdictional clai$\mathrm{ms}$ in published maps and institutional affiliations.

Copyright: (C) 2021 by the authors. Licensee MDPI, Basel, Switzerland. This article is an open access article distributed under the terms and conditions of the Creative Commons Attribution (CC BY) license (https:// creativecommons.org/licenses/by/ $4.0 /)$.

\begin{abstract}
Different $\mathrm{Ag} @ \mathrm{TiO}_{2}$ and $\mathrm{Ag} @ \mathrm{ZnO}$ catalysts, with nanowire $(\mathrm{NW})$ structure, were synthesized containing different amounts of silver loading (1, 3, 5, and $10 \mathrm{wt}$. $)$ ) and characterized by FE-SEM, HRTEM, BET, XRD, Raman, XPS, and UV-vis. The photocatalytic activity of the composites was studied by the production of hydrogen via water splitting under UV-vis light and the degradation of the antibiotic ciprofloxacin. The maximum hydrogen production of all the silver-based catalysts was obtained with a silver loading of $10 \mathrm{wt} . \%$ under irradiation at $500 \mathrm{~nm}$. Moreover, $10 \% \mathrm{Ag} @ \mathrm{TiO}_{2} \mathrm{NWs}$ was the catalyst with the highest activity in the hydrogen production reaction $(1119 \mu \mathrm{mol} / \mathrm{hg})$, being 18 times greater than the amount obtained with the pristine $\mathrm{TiO}_{2} \mathrm{NW}$ catalyst. The most dramatic difference in hydrogen production was obtained with $10 \% \mathrm{Ag} @ \mathrm{TiO}_{2}$ $\mathrm{P} 25,635 \mu \mathrm{mol} / \mathrm{hg}$, being 36 times greater than the amount reported for the unmodified $\mathrm{TiO}_{2}-\mathrm{P} 25$ $(18 \mu \mathrm{mol} / \mathrm{hg})$. The enhancement of the catalytic activity is attributed to a synergism between the silver nanoparticles incorporated and the high surface area of the composites. In the case of the degradation of ciprofloxacin, all the silver-based catalysts degraded more than $70 \%$ of the antibiotic in $60 \mathrm{~min}$. The catalyst that exhibited the best result was 3\%Ag@ZnO commercial, with 99.72\% of degradation. The control experiments and stability tests showed that photocatalysis was the route of degradation and the selected silver-based catalysts were stable after seven cycles, with less than $1 \%$ loss of efficiency per cycle. These results suggest that the catalysts could be employed in additional cycles without the need to be resynthesized, thus reducing remediation costs.
\end{abstract}

Keywords: photocatalysis; hydrogen production; ciprofloxacin; silver nanoparticles; $\mathrm{TiO}_{2} ; \mathrm{ZnO}$

\section{Introduction}

During the last decade, there has been a significant increase in discussions related to the production of energy from renewable sources [1,2]. This is mainly due to the increase in global temperatures and climate change, caused by the burning of fossil fuels and release of greenhouse gases such as carbon dioxide $\left(\mathrm{CO}_{2}\right)$ [2]. For this reason, countless efforts around the world have focused on developing technologies that allow the production of energy from renewable sources in a cost-effective way. Within these efforts, inspiration and answers are sought in nature. Materials that can mimic what nature has perfected over thousands or millions of years are investigated in the hope that they can be manufactured, used, developed, and employed upscale. 
Developing active and robust water oxidation catalysts is the key to constructing efficient artificial photosynthetic systems [3-6]. The oxidation of water is the primary and key reaction of overall water splitting, but it requires the transfer of 4 electrons $\left(\mathrm{e}^{-}\right)$and $4 \mathrm{H}^{+}$with continuous formation of $\mathrm{O}-\mathrm{O}$ bonds, leading to high energy barriers and slow kinetics [6]. Therefore, great efforts have been devoted to developing efficient catalysts, including homogeneous, heterogeneous, and especially biomimetic catalysts, to facilitate the oxygen evolution reaction (OER) in the past few decades [6].

In terms of biomimetics catalysts, water oxidation occurs in nature at the so-called $\mathrm{CaMn}_{4} \mathrm{O}_{5}$ oxygen evolution complexes surrounded by many amino acid residues in photosystem (II) (PSII) [5,6]. To date, water oxidation catalysts have been integrated into photocatalytic and photoelectrocatalytic (PEC) systems to construct artificial photosynthetic systems [4-6]. Selective deposition on special sites of light-harvesting semiconductors and interface engineering with charge transfers are some of the modifications that have been implemented to improve the efficiency of photosystems [6].

Semiconductors such as $\mathrm{TiO}_{2}$ and $\mathrm{ZnO}$ have been extensively used, mainly due to their nontoxicity, low cost, and high chemical stability [7-10]. One of the main disadvantages of using $\mathrm{TiO}_{2}$ and $\mathrm{ZnO}$ as photocatalysts is their wide band gap energy (i.e., $3.2 \mathrm{eV}$ for $\mathrm{TiO}_{2}$ anatase; $3.37 \mathrm{eV}$ for $\mathrm{ZnO}$ wurtzite). With these energy gaps, only UV light can be used $[8,9]$. This fact must be taken into consideration since only $4 \%$ of the total radiation that comes from the sun is in the UV region, whereas $50 \%$ is in the visible region of the electromagnetic spectrum [10]. It is for this reason that recent investigations have focused on modifying the band gap of the catalysts. Some of the chemical modifications include the doping of $\mathrm{TiO}_{2}$ and $\mathrm{ZnO}$ with metal and non-metal elements [7-10]. The incorporation of noble metals, such as silver $(\mathrm{Ag})$, on the surfaces of these semiconductors has gained substantial interest in recent years due to the ability of the noble metal nanoparticles to reduce the fast recombination of the photogenerated charge carriers, enabling the use of visible light [11-18]. By reducing the photogenerated charge carriers, the UV activity is increased due to the electron transfer from the conduction band (CB) of $\mathrm{TiO}_{2}$ or $\mathrm{ZnO}$ to the noble metal nanoparticles [12]. The photoactivity in the visible spectral range can be explained due to the surface plasmon resonance effect and charge separation by the transfer of photoexcited electrons from the metal nanoparticles to the $\mathrm{CB}$ of $\mathrm{TiO}_{2}$ or $\mathrm{ZnO}$ [11-18].

The development of silver-based catalysts $\left(\mathrm{Ag} @ \mathrm{TiO}_{2}\right.$ and $\left.\mathrm{Ag} @ \mathrm{ZnO}\right)$ for hydrogen production via water splitting and the degradation of organic pollutants have been attracting attention in recent years. For example, Saravanan et al. [12] synthesized Ag@ $\mathrm{TiO}_{2}$ photocatalysts for the production of hydrogen and degradation of methyl orange dye (MO). The catalysts exhibited good visible light activity and excellent stability over three cycles for the aqueous phase photocatalytic degradation of $\mathrm{MO}(38 \mu \mathrm{mol} / \mathrm{h} \mathrm{g})$ and excellent hydrogen production from water splitting $(910 \mu \mathrm{mol} / \mathrm{h} \mathrm{g})$. The results were justified by the incorporation of $\mathrm{Ag}$ onto $\mathrm{TiO}_{2}$, which improved the photophysical properties, narrowing the band gap and suppressing the charge carrier recombination. On the other hand, Mao et al. [14] synthesized $\mathrm{Ag} @ \mathrm{TiO}_{2}$ with different structures (nanoparticles, nanoflakes, and nanorods). The as-synthesized Ag@ $\mathrm{TiO}_{2}$ compounds were employed as catalysts for the photodegradation of $\mathrm{MO}$ under visible light irradiation, showing that $\mathrm{Ag} @ \mathrm{TiO}_{2}$ compounds display a catalytic performance superior to pure $\mathrm{TiO}_{2}$. The catalyst with $20 \mathrm{wt}$. \% Ag exhibited the best photocatalytic activity after 120 min of treatment, with photodegradations of ca. $98.9 \%$ for MO under visible light irradiation. This was explained by the fact that a suitable amount of Ag could restrain the recombination of the photoproduced charges and extend the range of the light absorption. Meanwhile, Mou et al. [15] developed three-dimensional (3D) Ag@ZnO assemblies with porous nanosheets as building blocks to produce hydrogen via water splitting and the degradation of 4-nitrophenol, demonstrating superior sunlightdriven photocatalytic activities, with nearly $100 \%$ degradation of 10 ppm 4-nitrophenol and $0.4436 \mathrm{mmol} \mathrm{g}^{-1} \mathrm{~h}^{-1}$ of hydrogen production. The authors attribute these results to the synergistic effect between 2D $\mathrm{ZnO}$ porous single crystalline nanosheets and silver, which could not only accelerate the separation and migration efficiency of charge carriers 
but also enhance the charge collection efficiency. Other authors [16] synthesized Ag@ZnO composites for the degradation of rhodamine $B$ and the production of hydrogen by water splitting. Under ultraviolet, visible-light, simulated sunlight, and microwave-assisted irradiation, the composite exhibited better photocatalytic properties for the photocatalytic degradation of rhodamine B compared to that of P25 and $\mathrm{ZnO}$. Moreover, the composite was investigated as a catalyst for the degradation of four dyes with different structures under UV conditions, exhibiting good degradation performance. In addition, the photocatalytic hydrogen production experiments showed that Ag@ZnO had some ability to produce photocatalytic hydrogen.

Ciprofloxacin is a fluoroquinolone which constitutes one of the major families of antibiotics [19]. Ciprofloxacin is employed for treating infectious diseases and is effective against both Gram-positive and Gram-negative bacteria. During their use in humans, these antibiotics are incompletely metabolized and are excreted mostly through urine and stool. Ciprofloxacin has been detected in appreciable quantities in continental waters and reservoirs, as it is a compound which is highly resistant to degradation. Antibiotics, and particularly ciprofloxacin, enter the body through drinking water, allowing bacteria to become resistant to these compounds. For these reasons, the purposes of this investigation were twofold: (1) to synthesize different weight percentages $(1,3,5$, and $10 \mathrm{wt} . \%)$ of silver-based catalysts $\left(\mathrm{Ag} @ \mathrm{TiO}_{2}\right.$ and $\left.\mathrm{Ag} @ \mathrm{ZnO}\right)$; and (2) to study the photocatalytic activity of the as-synthesized composites in two processes of current relevance-the production of hydrogen via water splitting and the photodegradation of ciprofloxacin.

\section{Materials and Methods}

\subsection{Reagents}

All reagents were used as received and all the experimental solutions were prepared using ultra-pure water (Milli-Q water, $18.2 \mathrm{M} \Omega \mathrm{cm}^{-1}$ at $25^{\circ} \mathrm{C}$ ). Acetone, isopropyl alcohol $+99.9 \%$, and $\mathrm{HCl} 37 \%$ (ACS Reagent) were provided by Acros Chemicals (Newark, NJ, USA). $\mathrm{TiCl}_{4}$ 99.9\% was obtained from Fisher Scientific (Pittsburgh, PA, USA). Degussa P25 (Degussa, nanopowder with 21-nm particle size, $35-65 \mathrm{~m}^{2} \cdot \mathrm{g}^{-1}$ surface area, $+99.5 \%$ ), $\mathrm{AgNO}_{3}\left(99.99+\%\right.$, trace metal basis), $\mathrm{Zn}\left(\mathrm{C}_{2} \mathrm{H}_{3} \mathrm{O}_{2}\right)_{2}$ (98+\%, ACS Reagent), and $\mathrm{NaBH}_{4}$ $+99.9 \%$ were provided by Sigma Aldrich (Milwaukee, WI USA). The commercial zinc oxide $(99.99 \%)$ was obtained from Alfa Aesar (Ward Hill, MA, USA). Si <100> substrates, p-type boron-doped, provided by El-CAT (Ridgefield Park, NJ, USA), were used as substrates for the hydrothermal growth of $\mathrm{TiO}_{2}$ nanowires $\left(\mathrm{TiO}_{2} \mathrm{NWs}\right)$. Finally, for the photocatalytic experiments, ciprofloxacin $\left(\mathrm{C}_{17} \mathrm{H}_{18} \mathrm{FN}_{3} \mathrm{O}_{3}, \geq 98 \% \mathrm{HPLC}\right), \mathrm{Na}_{2} \mathrm{~S} 99.9 \%$, and $\mathrm{Na}_{2} \mathrm{SO}_{3}+98 \%$ were also obtained from Sigma Aldrich (Milwaukee, WI, USA).

\subsection{Synthesis of $\mathrm{TiO}_{2}$ and $\mathrm{ZnO}$ Nanowires}

The synthesis of $\mathrm{TiO}_{2}$ NWs was carried out following the method described by Cotto et al. (2013) [20]. In a typical synthesis, $50 \mathrm{~mL}$ of concentrated hydrochloric acid and $50 \mathrm{~mL}$ of deionized water were mixed in a $200 \mathrm{~mL}$ Erlenmeyer flask. After this, $3 \mathrm{~mL}$ of the titanium precursor was added by dripping, under agitation, at room temperature. The mixture was magnetically stirred until all solid particles were dissolved (approximately $10 \mathrm{~min}$ ). Then, the solution was placed into 30-mL Teflon-lined stainless-steel autoclaves. Next, single crystal silicon substrates, $\mathrm{Si}\langle 100\rangle$, were introduced inside the autoclaves. Autoclaves were maintained at $180^{\circ} \mathrm{C}$ for $24 \mathrm{~h}$. The resulting $\mathrm{TiO}_{2} \mathrm{NWs}$, grown on the surfaces of the silicon wafers, were thoroughly washed with deionized water and dried overnight at $60{ }^{\circ} \mathrm{C}$.

In the case of the $\mathrm{ZnO}$ NWs, the synthesis consisted of the thermal decomposition of zinc acetate, according to the procedure used by $\mathrm{Lin}$ and $\mathrm{Li}$ (2009) [21]. For this, $0.5 \mathrm{~g}$ of zinc acetate dihydrate was heat-treated at $300{ }^{\circ} \mathrm{C}$ for $3 \mathrm{~h}$ in an alumina crucible. After the reaction time, the crucible was left to cool down and the product was then collected and sealed at room temperature. 


\subsection{Incorporation of Silver Nanoparticles ( $A g N P s$ )}

The incorporation of $\mathrm{Ag}$ NPs onto the surfaces of $\mathrm{TiO}_{2} \mathrm{NWs}, \mathrm{TiO}_{2}-\mathrm{P} 25, \mathrm{ZnO} \mathrm{NWs}$, and $\mathrm{ZnO}$ commercial catalysts consisted of a modification of the method described by Naldoni et al. [22]. A typical synthesis consisted of dispersing $500 \mathrm{mg}$ of the desired catalyst in $40 \mathrm{~mL}$ of $\mathrm{H}_{2} \mathrm{O}$ and subsequent treatment with ultrasound for $20 \mathrm{~min}$. After this, the desired amount of the silver precursor was added to the reaction mixture and stirred for $30 \mathrm{~min}$. Finally, a $\mathrm{NaBH}_{4}$ solution $\left(10 \mathrm{mg}\right.$ in $10 \mathrm{~mL}$ of $\left.\mathrm{H}_{2} \mathrm{O}\right)$ was added dropwise, under stirring, and allowed to react for $10 \mathrm{~min}$ at room temperature. The reaction product was centrifuged, washed three times with deionized water, and dried overnight at $60^{\circ} \mathrm{C}$. The different silver-based composites were identified as x\%Ag@TiO $\mathrm{NWs}_{2} \mathrm{~N} \% \mathrm{Ag} @ \mathrm{TiO}_{2}-\mathrm{P} 25$, $\mathrm{x} \% \mathrm{Ag} @ \mathrm{ZnO} N W \mathrm{~s}, \mathrm{x} \% \mathrm{Ag} @ \mathrm{ZnO}$ commercial. The numbers $(\mathrm{x} \%)$ correspond to the weight percentage of Ag NPs in the sample.

\subsection{Characterization of the Catalysts}

The catalysts were fully characterized by electron microscopy, using field-emission scanning electron microscopy (FE-SEM, Philips XL30 S-FEG; Chatsworth, CA, USA) and high-resolution transmission electron microscopy (HRTEM, JEOL 3000F; Peabody, MA, USA). XPS measurements were obtained on an ESCALAB 220i-XL spectrometer (Waltham, MA, USA), by using the non-monochromated $\mathrm{Mg} \mathrm{K} \alpha(1253.6 \mathrm{eV})$ radiation of a twin-anode, operating at $20 \mathrm{~mA}$ and $12 \mathrm{kV}$ in the constant analyzer energy mode, with a PE of $50 \mathrm{eV}$. Brunauer-Emmett-Teller (BET) specific surface areas were measured using a Micromeritics ASAP 2020 (Norcross, GA, USA), according to $\mathrm{N}_{2}$ adsorption isotherms, at $77 \mathrm{~K}$. Raman measurements were acquired using a DXR Thermo Raman Microscope (Waltham, MA, USA), employing a 532-nm laser source at 5-mW power and a nominal resolution of $5 \mathrm{~cm}^{-1}$. $\mathrm{X}$-ray diffraction $(\mathrm{XRD})$ patterns were obtained in theta/2theta configuration in the range of $20-80^{\circ}$ at $2^{\circ} \mathrm{min}^{-1}$, using a Bruker D8 Advance X-Ray Diffractometer (Billerica, MA, USA), operating at $40 \mathrm{kV}$ and $40 \mathrm{~mA}$. The UV-vis spectra were measured using a Shimadzu UV-1800PC spectrophotometer (Missouri City, TX, USA).

\subsection{Photocatalytic Experiments}

The hydrogen production via water splitting experiments consisted of the following: $100 \mathrm{~mL}$ of deionized water was added to a $200 \mathrm{~mL}$ quartz reactor flask. Then, $50 \mathrm{mg}$ of the silver-based catalyst was added to the flask containing the water. Solutions of $0.5 \mathrm{M}$ $\mathrm{Na}_{2} \mathrm{~S}$ and $0.03 \mathrm{M} \mathrm{Na}_{2} \mathrm{SO}_{3}$ were added as sacrificial reagents to promote photocatalytic activity and increase $\mathrm{H}_{2}$ production, due to their action as hole scavengers [23,24]. The reaction mixture was thermostatized at $20^{\circ} \mathrm{C}$, magnetically stirred at $20 \mathrm{rpm}$, and purged with nitrogen for at least $20 \mathrm{~min}$. Then, the solution was exposed to UV-vis radiation for $120 \mathrm{~min}$ using different filters to select the appropriate irradiation wavelength. The produced hydrogen was collected, using nitrogen as gas carrier, and was identified and quantified by Gas Chromatography with a Thermal Conductivity Detector (GC-TCD, Perkin-Elmer Clarus 600; Shelton, CT, USA).

For the photocatalytic degradation experiments, a solar simulator composed of two annular white bulb lights with a total irradiation power of 60 watts was used. A solution of $1 \times 10^{-5} \mathrm{M}$ of ciprofloxacin was prepared and then the desired catalyst was added. After adding the catalyst and adjusting the $\mathrm{pH}$ to 7 , the system was kept in the dark for $30 \mathrm{~min}$ to let the system reach adsorption-desorption equilibrium. Then, a small amount of $\mathrm{H}_{2} \mathrm{O}_{2}$ ( $3 \mathrm{~mL}, 0.005 \%$ ) was added; additional oxygen was provided to the system by constant air-bubbling. The white bulb lights were switched on, and the photocatalytic system was maintained under constant stirring and irradiation. The reaction was monitored for a period of $60 \mathrm{~min}$, and the kinetics of photodegradation was studied by taking aliquots every $10 \mathrm{~min}$. After filtering the aliquots with $0.45-\mu \mathrm{m}$ membrane filters, the samples were analyzed with a Shimadzu UV-1800PC spectrophotometer. 


\section{Results and Discussion \\ 3.1. Characterization of Catalysts}

Figure 1 shows different FE-SEM images of $\mathrm{TiO}_{2} \mathrm{NWs}$ and $\mathrm{ZnO}$ NWs at different magnifications. The as-synthesized $\mathrm{TiO}_{2} \mathrm{NWs}$ consist of homogeneous and highly branched structures (Figure 1A). At higher magnifications (Figure 1B), $\mathrm{TiO}_{2} \mathrm{NWs}$ have a squarelike form and are composed of smaller units with the same shape. The specific surface area of the catalyst obtained by BET measurements was $403 \mathrm{~m}^{2} \mathrm{~g}^{-1}$, a large area that may be justified by the highly branched structures and could have relevant effects on the catalytic properties of this material. The FE-SEM images of $\mathrm{ZnO}$ catalysts are shown in Figure 1C. ZnO NWs consisted of non-homogenous wires, with differences in size and length. The BET surface area of $\mathrm{ZnO} N W s\left(160 \mathrm{~m}^{2} \mathrm{~g}^{-1}\right)$ was clearly less than that observed for $\mathrm{TiO}_{2} \mathrm{NWs}$.
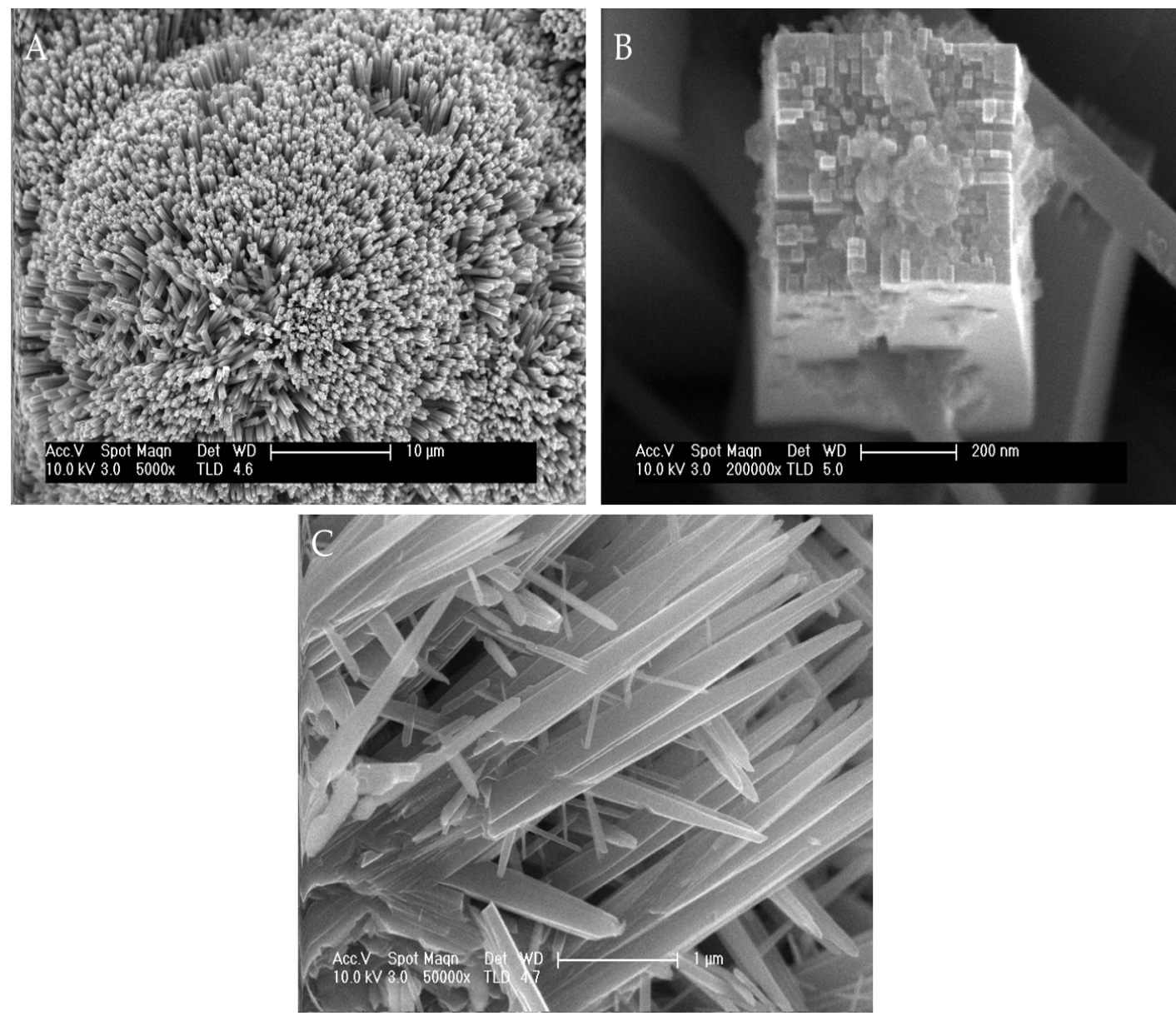

Figure 1. Field emission scanning electron microscopy (FE-SEM) images of the as-synthesized $\mathrm{TiO}_{2} \mathrm{Nanowires} \mathrm{NWs}$ ) at $5000 \times(\mathbf{A}), 20,000 \times(\mathbf{B})$, and $\mathrm{ZnO} \mathrm{NWs}$ at $5000 \times(\mathbf{C})$.

After the synthesis of $\mathrm{TiO}_{2} \mathrm{NWs}$ and $\mathrm{ZnO}$ NWs catalysts, different amounts of $\mathrm{Ag}$ NPs (1\%, 3\%, 5\%, and 10\% wt. $\%)$ were deposited onto the surfaces of the as-synthesized catalysts and their commercial forms $\left(\mathrm{TiO}_{2}-\mathrm{P} 25\right.$ and commercial $\left.\mathrm{ZnO}\right)$ for comparison purposes, using a chemical reduction method. Figure 2 shows the high-resolution transmission electron microscopy (HRTEM) images of the catalysts containing $10 \mathrm{wt} . \%$ of Ag. All silver-based catalysts showed a non-homogenous distribution of the metal on the surface, with diameters of ca. $<10 \mathrm{~nm}$ (Figure 2). This is a normal characteristic when using sodium borohydride $\left(\mathrm{NaBH}_{4}\right)$ as a reducing agent, and it has been documented in previous works [25-27]. The $10 \% \mathrm{Ag} @ \mathrm{TiO}_{2}-\mathrm{P} 25$ (Figure 2A) and $10 \% \mathrm{ZnO}$ commercial (Figure 2C) composites consisted of supports of different shapes and sizes, of micrometers 
in length, and both the $10 \% \mathrm{Ag} @ \mathrm{TiO}_{2} \mathrm{NWs}$ (Figure 2B) and 10\%ZnO NWs (Figure 2D) showed significant changes in their morphology compared to the bare catalysts shown in Figure 1. These changes were expected and are also attributed to the synthesis process.
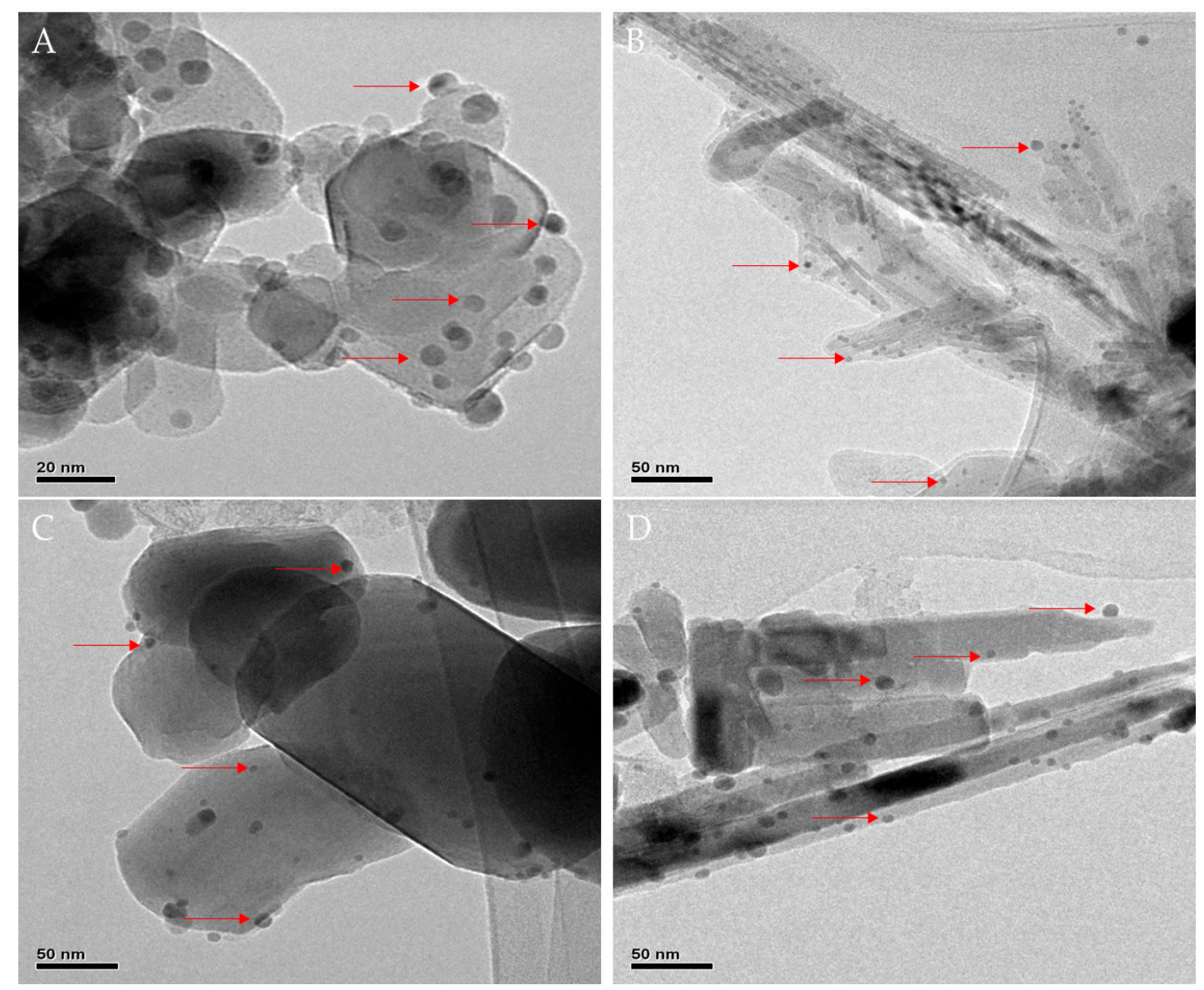

Figure 2. High-resolution transmittance electron microscopy (HRTEM) images of $10 \% \mathrm{Ag} @ \mathrm{TiO}_{2}-\mathrm{P} 25$ (A), $10 \% \mathrm{Ag} @ \mathrm{TiO} 2$ NWs (B), 10\%Ag@ZnO commercial (C), and 10\%Ag@ZnO NWs (D) catalysts. The red arrows indicate the presence of Ag Nanoparticles (NPs).

The BET surface areas of the silver-based catalysts with different Ag loadings were analyzed and the results are shown in Table 1. Before the silver deposition, the average surface areas of the as-synthesized $\mathrm{TiO}_{2} \mathrm{NWs}$ and $\mathrm{ZnO}$ NWs were 403 and $160 \mathrm{~m}^{2} \cdot \mathrm{g}^{-1}$, respectively, whereas the surface areas of the commercial ones $\left(\mathrm{TiO}_{2}-\mathrm{P} 25\right.$ and $\left.\mathrm{ZnO}\right)$ were 53 and $18 \mathrm{~m}^{2} \cdot \mathrm{g}^{-1}$, respectively. These results clearly show that the synthesis processes used to obtain $\mathrm{TiO}_{2} \mathrm{NWs}$ and $\mathrm{ZnO}$ NWs allowed us to obtain high-surface supports. Unexpectedly, the addition of silver nanoparticles on the pristine catalysts resulted in an increase in surface area. This effect is much more significant in composites with the highest percentage of silver on the surface (see Table 1). As was determined by HRTEM, these nanoparticles are dispersed on the surfaces of the catalysts, suggesting that the chemical reduction approach is an efficient method for synthesizing these composites.

The XRD patterns of pristine catalysts and catalysts with $10 \mathrm{wt} . \% \mathrm{Ag}$ are shown in Figure 3. Figure $3 \mathrm{~A}$, corresponding to $\mathrm{TiO}_{2} \mathrm{NWs}$ (pristine or with $10 \mathrm{wt.} \% \mathrm{Ag}$ ), shows intense peaks at $27^{\circ}(110), 36^{\circ}(101)$, and $55^{\circ}$ (211), which have been unambiguously ascribed to the rutile phase (JCPDS 88-1175) [28]. The $10 \% \mathrm{Ag} @ \mathrm{TiO}_{2} \mathrm{NW}$ diffractogram, as well as the rest of the catalysts with other percentages of silver, showed a small shift towards lower angles compared to the pure $\mathrm{TiO}_{2} \mathrm{NWs}$. This displacement has been attributed to the incorporation of the silver nanoparticles on the surface of the support [29]. No silver 
peak was observed at low silver loading $\left(1 \% \mathrm{Au} @ \mathrm{TiO}_{2} \mathrm{NWs}\right.$ and $\left.3 \% \mathrm{Au} @ \mathrm{TiO}_{2} \mathrm{NWs}\right)$. Only $10 \% \mathrm{Ag} @ \mathrm{TiO}_{2} \mathrm{NWs}$ presented two peaks at ca. $38^{\circ}$ (111) and $46^{\circ}(200)$, ascribed to the presence of silver nanoparticles with fcc unit cell.

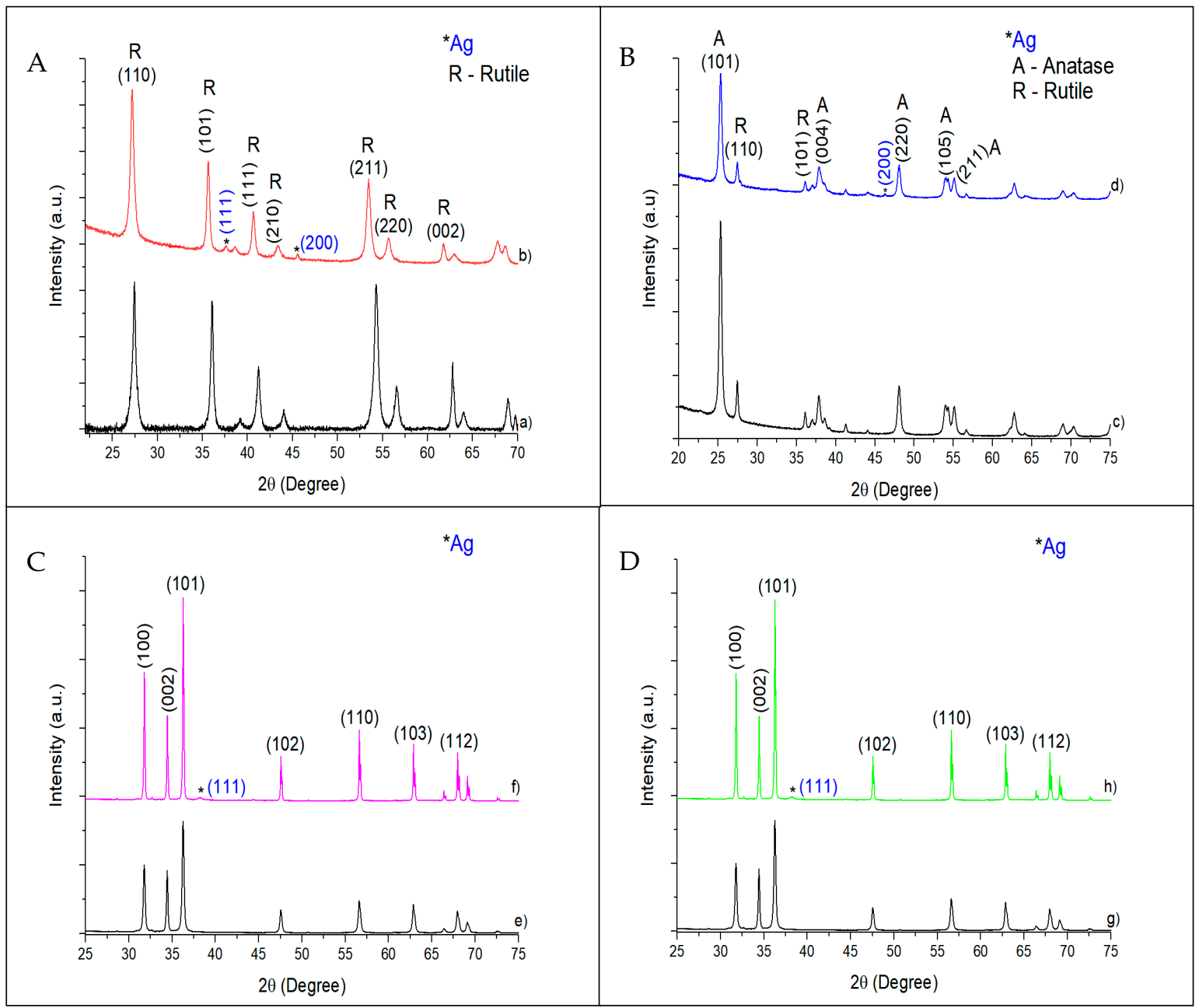

Figure 3. X-ray diffraction patterns (XRD) of $\mathrm{TiO}_{2} \mathrm{NW}(\mathbf{A}, \mathrm{a}), 10 \% \mathrm{Ag} @ \mathrm{TiO}_{2} \mathrm{NW}(\mathbf{A}, \mathrm{b}), \mathrm{TiO}_{2}-\mathrm{P} 25(\mathbf{B}, \mathrm{c}), 10 \% \mathrm{Ag} @ \mathrm{TiO} 2-\mathrm{P} 25$ (B,d), ZnO commercial (C,e), 10\%Ag@ZnO commercial (C,f), ZnO NW (D,g), and 10\%Ag@ZnO NW (D,h) catalysts.

Table 1. Brunauer, Emmett and Teller (BET) surface area of the silver-based catalysts.

\begin{tabular}{ccccc}
\hline & $\begin{array}{c}\mathrm{TiO}_{\mathbf{2}}-\mathbf{P 2 5} \\
\left(\mathbf{m}^{\mathbf{2}} \cdot \mathbf{g}^{-\mathbf{1}}\right)\end{array}$ & $\begin{array}{c}\mathrm{ZnO} \text { Commercial } \\
\left(\mathbf{m}^{\mathbf{2}} \cdot \mathbf{g}^{-\mathbf{1}} \mathbf{)}\right.\end{array}$ & $\begin{array}{c}\mathrm{TiO}_{\mathbf{2}} \mathbf{N W s} \\
\left(\mathbf{m}^{\mathbf{2}} \cdot \mathbf{g}^{-\mathbf{1}}\right)\end{array}$ & $\begin{array}{c}\mathbf{Z n O} \mathbf{~ N W s} \\
\left(\mathbf{m}^{\mathbf{2}} \cdot \mathbf{g}^{-\mathbf{1}} \mathbf{)}\right.\end{array}$ \\
\hline $0 \%$ Bare $)$ & 53 & 18 & 403 & 160 \\
$1 \% A g$ & 63 & 78 & 417 & 167 \\
$3 \% A g$ & 72 & 81 & 426 & 179 \\
$5 \% A g$ & 81 & 99 & 438 & 194 \\
$10 \% A g$ & 89 & 112 & 443 & 202 \\
\hline
\end{tabular}

$\mathrm{TiO}_{2}-\mathrm{P} 25$ is a mixture of $70 \%$ anatase and $30 \%$ rutile. The characteristic peaks of anatase (JCPDS 21-1272) can be found at ca. $25^{\circ}(101), 38^{\circ}(004), 48^{\circ}(220), 54^{\circ}(105)$, and $55^{\circ}$ (211) [28], while the rutile crystalline phase has its characteristic peaks at ca. $27^{\circ}(110)$, $36^{\circ}(101), 41^{\circ}(111)$, and $54^{\circ}$ (211) (JCPDS 34-180) [28]. All the peaks corresponding to both anatase and rutile are present in the diffraction pattern of Figure 3B-D. The characteristic peak of rutile (ca. $27^{\circ}$ ) was not present in any silver loadings. Only the $10 \% \mathrm{Ag} @ \mathrm{TiO}_{2}-\mathrm{P} 25$ showed one peak assigned to the face-centered cubic (fcc) structure of the adsorbed Ag metal nanoparticles corresponding to the $\mathrm{h} \mathrm{k} l$ parameters (200) at ca. $46^{\circ}$ [30]. 
The XRD patterns of silver-based $\mathrm{ZnO}$ NWs and commercial $\mathrm{ZnO}$ did not show major differences (Figure 3C,D). Peaks shown at ca. $32^{\circ}(100), 34.8^{\circ}(002), 36^{\circ}(101), 47.5^{\circ}$ $(102), 56.2^{\circ}(110), 62.8^{\circ}(103), 66^{\circ}(200), 67.5^{\circ}(112)$, and $68.8^{\circ}(201)$ were ascribed to the $\mathrm{ZnO}$ wurtzite phase (JCPDS 396-1451) [31]. The presence of silver nanoparticles was only detected in 10\%Ag@ZnO commercial and 10\%Ag@ZnO NWs at ca. $38^{\circ}(111)$ and not in catalysts with lower silver percentages.

Figure 4 shows the Raman spectra of pristine catalysts and catalysts with $10 \mathrm{wt}$ \% Ag. The anatase phase shows major bands at ca. 150, 395, 515, and $638 \mathrm{~cm}^{-1}$ [32] that can be observed in the bare $\mathrm{TiO}_{2}-\mathrm{P} 25$ and 10\%Ag@ $@ \mathrm{TiO}_{2}-\mathrm{P} 25$ (Figure 4A, a,b) catalysts, being attributed to the five Raman-active modes of the anatase phase, corresponding to $\mathrm{E}_{\mathrm{g}(1)}$, $\mathrm{B}_{1 \mathrm{~g}(1)}, \mathrm{A}_{1 \mathrm{~g}}+\mathrm{B}_{1 \mathrm{~g}(2)}$, and $\mathrm{E}_{\mathrm{g}(2)}$ vibrational modes. The typical Raman bands resulting from the rutile phase appear at ca. $143 \mathrm{~cm}^{-1}$ (superimposed with the $145 \mathrm{~cm}^{-1}$ band from the anatase), 235, 455, and $612 \mathrm{~cm}^{-1}$ and have been ascribed to the $\mathrm{B}_{1 \mathrm{~g}}, \mathrm{E}_{\mathrm{g}}$, and $\mathrm{A}_{1 \mathrm{~g}}$ vibrational modes [32]. In the case of the 10\%Ag@ $\mathrm{TiO}_{2}-\mathrm{P} 25$ (Figure 4A,b), and in catalysts with lower percentages of silver, the peak corresponding to the presence of silver nanoparticles was not detected. The only change observed by increasing the silver loading of the samples was a slight decrease in the intensity of the characteristic peaks. This effect has been attributed directly to the presence of silver [33]. In $\mathrm{TiO}_{2} \mathrm{NWs}$ (Figure 4B,c), the characteristic Raman bands of $\mathrm{TiO}_{2}$ rutile can be found at ca. 275 and $475 \mathrm{~cm}^{-1}$ [34]. As can be seen in Figure $4 \mathrm{~B}, \mathrm{c}$, these bands are present, confirming that rutile is the only crystalline phase identified in the as-synthesized $\mathrm{TiO}_{2}$ NWs. As already shown before for catalysts based on P25, no peaks corresponding to the presence of silver nanoparticles were detected (see Figure 4B,d).

In the case of commercial $\mathrm{ZnO}$ and $\mathrm{ZnO} \mathrm{NWs}$, no relevant differences were observed (Figure 4C,D). The wurtzite phase shows main bands at ca. 327, 378, 437, and $1050 \mathrm{~cm}^{-1}$ [35]. The $1150 \mathrm{~cm}^{-1}$ band, observed in both the commercial catalyst (Figure $4 \mathrm{C}, \mathrm{e}$ ) and the assynthesized ZnO NWs (Figure 4D,g), has been attributed to overtones and/or combination bands [36]. The narrow strong band at $437 \mathrm{~cm}^{-1}$ was assigned to the $E_{2}$ modes, involving mainly $\mathrm{Zn}$ motion, corresponding to the band characteristic of the wurtzite phase [34]. The band at $378 \mathrm{~cm}^{-1}$ was ascribed to the $\mathrm{A}_{1 \mathrm{~T}}$ mode, indicating some degree of structural disorder in the $\mathrm{ZnO}$ lattice [36]. No bands associated with Ag NPs were detected in 10\%Ag@ZnO commercial (Figure 4C,f), 10\%ZnO NWs (Figure 4D,h), or in catalysts with lower percentages of silver.

The two catalyst systems were also characterized by XPS. Figure 5 shows the most relevant transitions of each system, considering the catalysts with the highest silver load (10\%Ag@ZnO NWs and 10\%Ag@ $\mathrm{TiO}_{2} \mathrm{NWs}$ ). Figure 5A shows the transitions corresponding to $\mathrm{Ti} 2 \mathrm{p}$ of the $10 \% \mathrm{Ag} @ \mathrm{TiO}_{2} \mathrm{NW}$ catalyst. The peaks observed at 464.5 and $458.8 \mathrm{eV}$ have been unambiguously assigned to $\mathrm{Ti}^{4+}$, typical of rutile $\mathrm{TiO}_{2}$, as identified by XRD [36,37]. In this catalyst, the O1s clearly shows two components at 530.1 and $531.4 \mathrm{eV}$. The lowest bond energy peak has been assigned to $\mathrm{O}^{2-}$ ions in the Ti-O bonds. The shoulder around $531.4 \mathrm{eV}$ has been assigned to $\mathrm{O}^{2-}$ ions in the oxygen-deficient regions, as previously referenced in the literature [36,37]. Figure 5C shows the transitions corresponding to Ag3d, with peaks at 374 and $368 \mathrm{eV}$, and a characteristic spin-orbit splitting of $6.0 \mathrm{eV}$, which have been clearly assigned to metallic Ag [36,37]. In the case of the 10\%Ag@ZnONWs catalyst, the result obtained was also as expected. Figure 5D shows a peak at $1022.1 \mathrm{eV}$, corresponding to the $\mathrm{Zn} 2 \mathrm{p}_{3 / 2}$ transition, which has been assigned to $\mathrm{Zn}^{2+}$ in $\mathrm{ZnO}$ [36,37]. As was the case with the rutile-based catalyst, the peak corresponding to the O1s transition also shows two components: a main component at $530.1 \mathrm{eV}$, assigned to oxygen in $\mathrm{Zn}-\mathrm{O}$ bonds, and a shoulder at ca. $531.3 \mathrm{eV}$ that has been assigned to $\mathrm{O}^{2-}$ ions in the oxygen-deficient regions $[17,38]$. In this catalyst, and as can be deduced from the deconvolution carried out (see Figure 5B,E), the ratio corresponding to the shoulder/main peak is lower than in the case of the rutile-based catalyst, which undoubtedly has implications for the catalytic behavior [36,37]. Finally, as with the rutile-based catalyst, the Ag nanoparticles on the surface are found as metallic silver (see Figure 5F). 


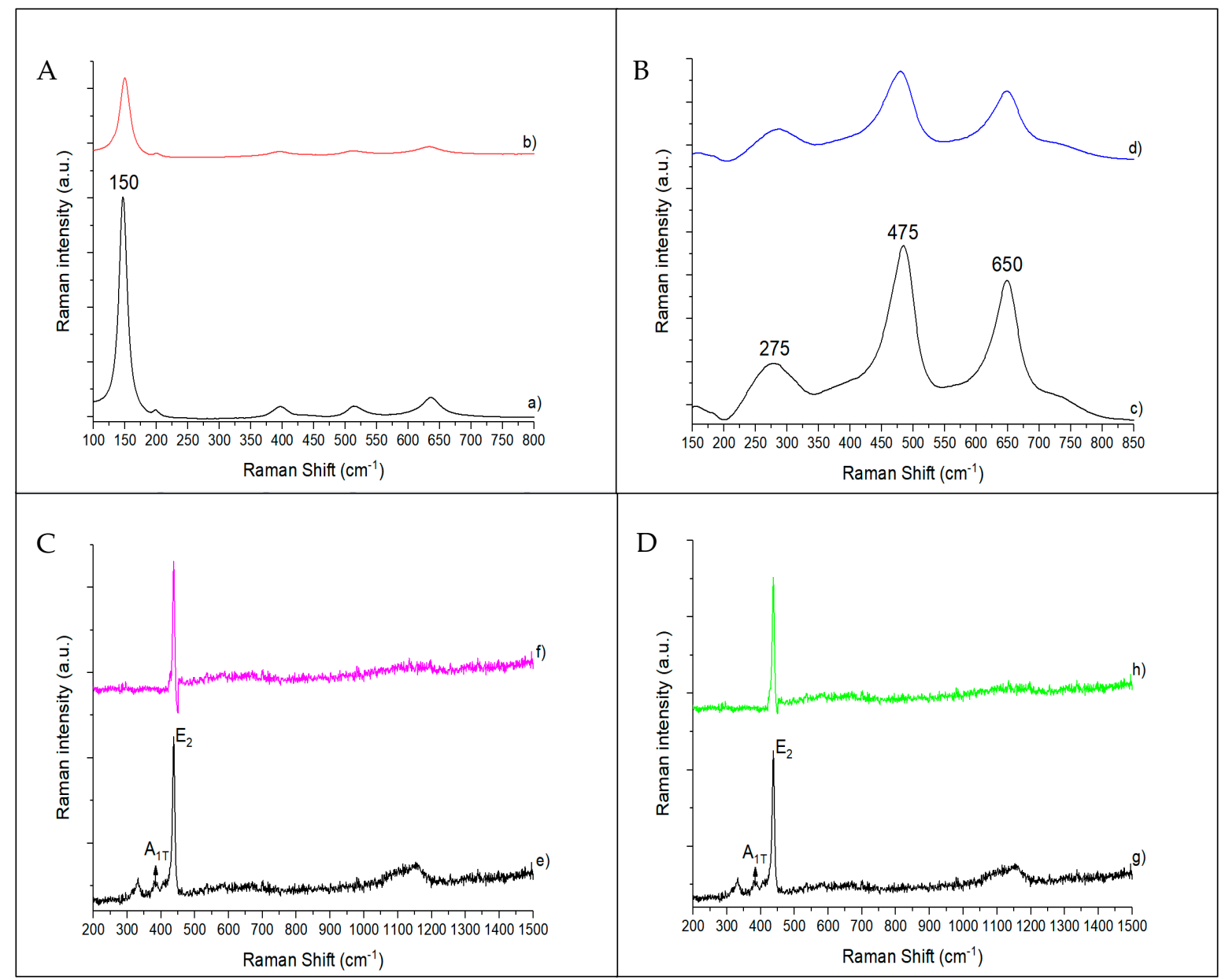

Figure 4. Raman spectra of $\mathrm{TiO}_{2}-\mathrm{P} 25$ (A,a), 10\%Ag@ $\mathrm{TiO}_{2}-\mathrm{P} 25$ (A,b), $\mathrm{TiO}_{2}$ NWs (B,c), 10\%Ag@TiO 2 NWs (B,d), ZnO commercial (C,e), 10\%Ag@ZnO commercial (C,f), ZnO NWs (D,g), and 10\%Ag@ZnO NWs (D,h) catalysts.
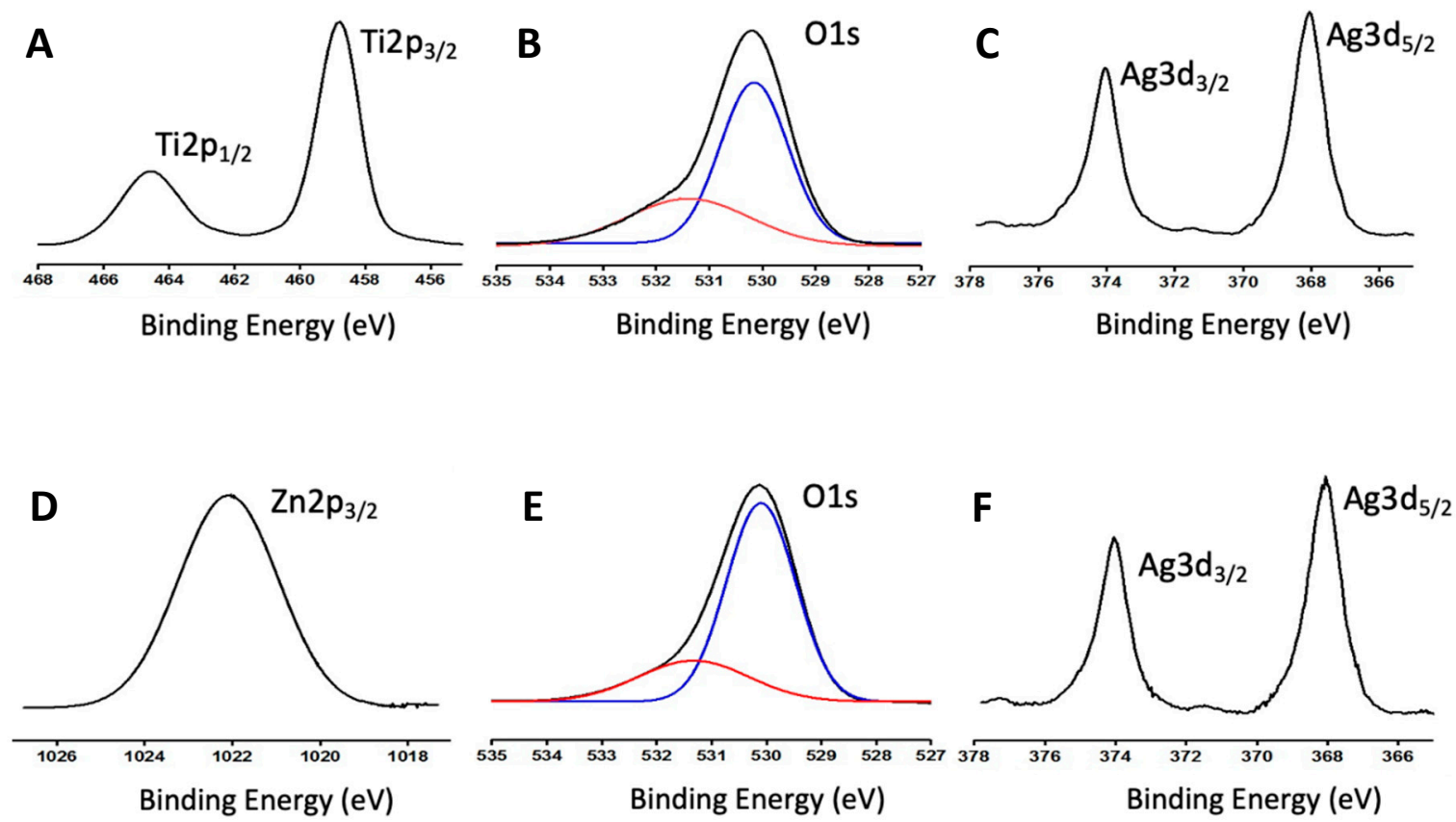

Figure 5. X-ray photoelectron spectroscopy (XPS) spectra of Ti 2 $\mathrm{p}_{1 / 2}, \mathrm{O} 1 \mathrm{~s}, \mathrm{Ag} 3 \mathrm{~d}_{3 / 2}, \mathrm{Ag} 3 \mathrm{~d}_{5 / 2}$ taken from the 10\%Ag@TiO 2 NW catalyst (A-C), and Zn 2 $\mathrm{p}_{1 / 2}, \mathrm{O} 1 \mathrm{~s}, \mathrm{Ag}_{3} \mathrm{~d}_{3 / 2}$, and $\mathrm{Ag}_{3} \mathrm{~d}_{5 / 2}$ taken from the $10 \% \mathrm{ZnO}$ NW composite (D-F). 
The pristine catalysts and catalysts with $10 \mathrm{wt}$.\% were also characterized by UV-vis spectroscopy (see Figure 6). The main absorption of $\mathrm{TiO}_{2}$ (Figure 6A) was observed at ca. $300 \mathrm{~nm}$, showing low absorption efficiency in the visible range. No additional absorption peaks were detected for any of the $\mathrm{Ag} @ \mathrm{TiO}_{2}-\mathrm{P} 25$ (Figure 6A,b) and $\mathrm{Ag} @ \mathrm{TiO}_{2} \mathrm{NW}$ (Figure $6 \mathrm{~A}, \mathrm{c}$ ) catalysts. This result is justified by the limited sensitivity of the spectrophotometer and the small size of the Ag NPs [39].

In the case of $\mathrm{ZnO}$ catalysts, the maximum absorption was observed at ca. $360 \mathrm{~nm}$ (Figure $6 \mathrm{~B}, \mathrm{~d}, \mathrm{e}, \mathrm{f}$ ), with very low absorption efficiency in the visible region. As with $\mathrm{TiO}_{2}-$ based catalysts, no peaks associated with the presence of Ag NPs were observed.
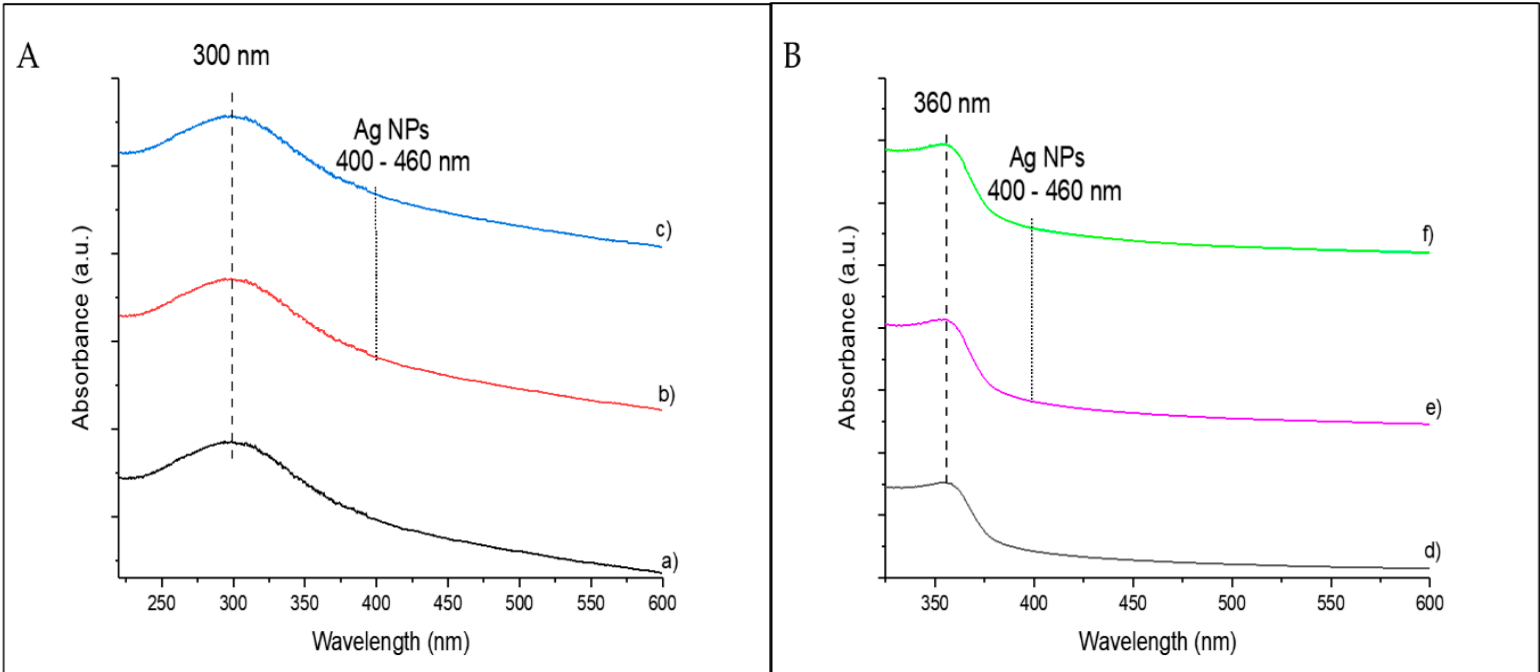

Figure 6. UV-vis spectra of $\mathrm{TiO}_{2} \mathrm{NW}(\mathbf{A}, \mathrm{a}), 10 \% \mathrm{Ag} @ \mathrm{TiO}_{2}-\mathrm{P} 25(\mathbf{A}, \mathrm{b}), 10 \% \mathrm{Ag} @ \mathrm{TiO}_{2} \mathrm{NW}(\mathrm{A}, \mathrm{c}), \mathrm{ZnO} \mathrm{NW}(\mathbf{B}, \mathrm{d}), 10 \% \mathrm{Ag} @ \mathrm{ZnO}$ commercial $(\mathbf{B}, \mathrm{e})$, and 10\%Ag@ZnO NW (B,f) catalysts. The region in which the presence of Ag NPs should be observed is indicated.

\subsection{Photocatalytic Hydrogen Production via Water Splitting}

The photocatalytic hydrogen production of the unmodified and silver-based catalysts at wavelengths of 300, 400, and $500 \mathrm{~nm}$ is shown in Figure 7. At $320 \mathrm{~nm}$, the highest hydrogen production was obtained with the 10\%Ag@ZnO NWs $(795 \mu \mathrm{mol} / \mathrm{hg})$, followed by $10 \% \mathrm{Ag} @ \mathrm{TiO}_{2} \mathrm{NWs}(758 \mu \mathrm{mol} / \mathrm{hg}), 10 \% \mathrm{Ag} @ \mathrm{TiO}_{2}-\mathrm{P} 25$ (575 $\left.\mu \mathrm{mol} / \mathrm{hg}\right)$, and 10\%Ag@ZnO commercial $(483 \mu \mathrm{mol} / \mathrm{hg})$, respectively. When compared with the production of the unmodified catalysts, all the silver-based catalysts increased their hydrogen production over $420 \mu \mathrm{mol} / \mathrm{hg}$, with the $10 \% \mathrm{Ag} @ \mathrm{TiO}_{2} \mathrm{NWs}$ catalyst being the one with the highest difference, $702 \mu \mathrm{mol} / \mathrm{hg}$. This represented an increase that was 13.5 times greater than bare $\mathrm{TiO}_{2}$ NWs. More details can be found in Table 2.

Table 2. Silver-based catalysts with the highest hydrogen production and their difference from the unmodified supports at a wavelength of $320 \mathrm{~nm}^{*}$.

\begin{tabular}{|c|c|c|c|c|}
\hline Catalyst & $\begin{array}{c}\text { Maximum } \mathrm{H}_{2} \\
\text { Production; } \\
\text { Silver-Based Catalysts } \\
(\mu \mathrm{mol} / \mathrm{gh})\end{array}$ & $\begin{array}{c}\text { Maximum } \mathrm{H}_{2} \\
\text { Production; } \\
\text { Unmodified Catalyst } \\
(\mu \mathrm{mol} / \mathrm{gh})\end{array}$ & $\begin{array}{c}\text { Difference in } \mathrm{H}_{2} \\
\text { Production }(\mu \mathrm{mol} / \mathrm{gh})\end{array}$ & $\begin{array}{l}\text { Times Greater Than } \\
\text { Unmodified Catalyst }\end{array}$ \\
\hline $10 \% \mathrm{AgTiO}_{2} \mathrm{NWs}$ & 758 & $\mathrm{TiO}_{2} \mathrm{NWs} ; 56$ & 702 & 13.53 \\
\hline $10 \% \mathrm{AgTiO}_{2}-\mathrm{P} 25$ & 575 & $\mathrm{TiO}_{2}-\mathrm{P} 25 ; 103$ & 389 & 5.58 \\
\hline $10 \% A g Z n O$ NWs & 795 & ZnO NWs; 365 & 430 & 2.18 \\
\hline $10 \% \mathrm{AgZnO}$ comm ** & 483 & $\mathrm{ZnO}$ Comm * 66 & 417 & 7.32 \\
\hline
\end{tabular}




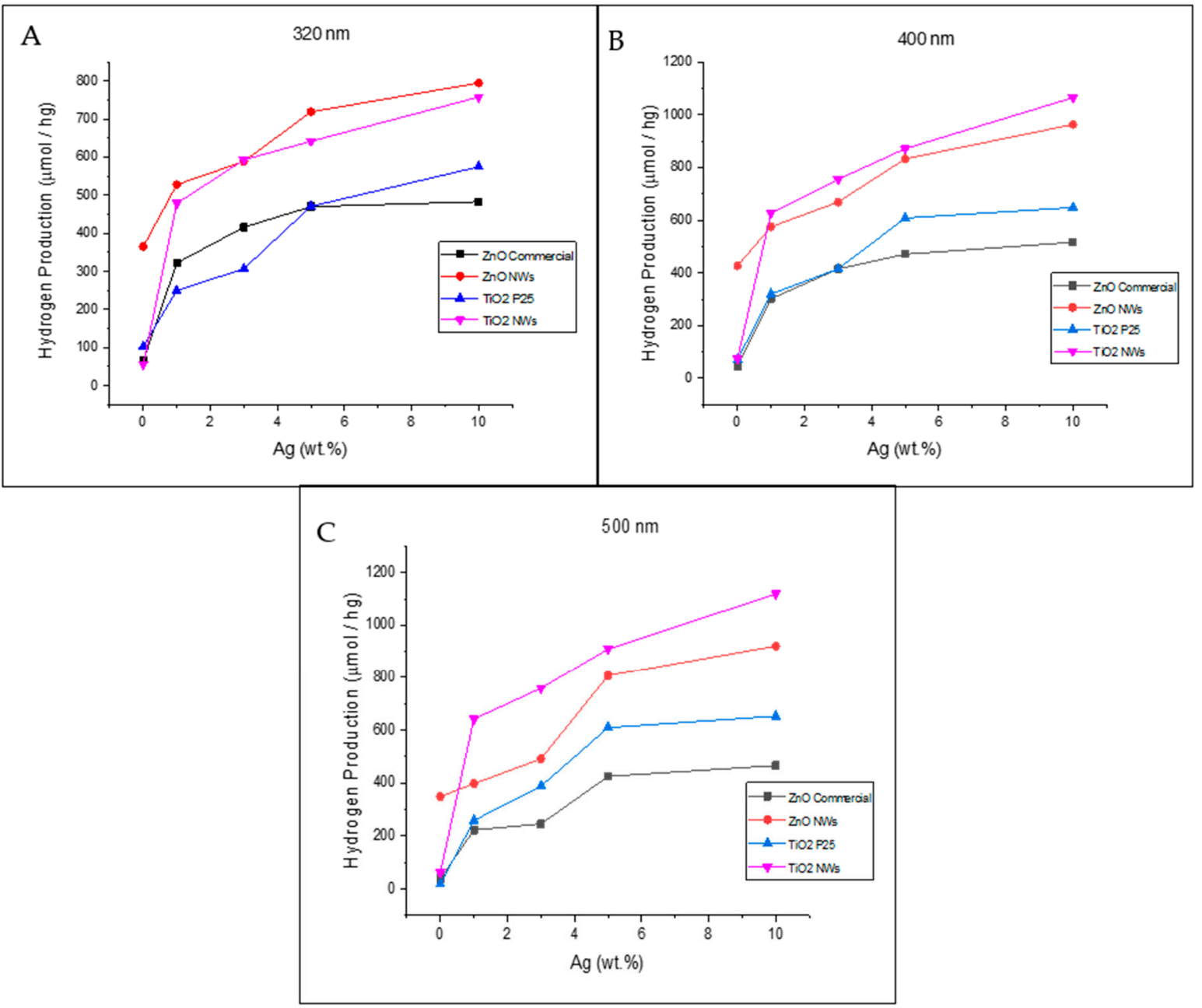

Figure 7. Photocatalytic hydrogen production of the different silver-based catalysts under irradiation at 320 (A), 400 (B), and $500 \mathrm{~nm}(\mathbf{C})$.

In all cases, the highest amount of hydrogen was obtained with a silver load of $10 \%$ by weight, indicating that even higher hydrogen production could be obtained with higher silver loadings. Another important aspect is that the highest hydrogen production was obtained with the catalyst of higher surface area. Different studies [34,40-43] have found that a key factor in the photocatalytic activity of semiconductors, such as $\mathrm{TiO}_{2}$ and $\mathrm{ZnO}$, is their high surface area. A high surface area leads to a higher density of localized states [34], which involve electrons with energies between the conduction and valence bands. These electrons are present due to terminated and unsaturated bonds on the surfaces, providing beneficial charge separation in the form of trapping sites for photogenerated charge carriers [34]. Although the $10 \% \mathrm{Ag} @ \mathrm{TiO}_{2} \mathrm{NW}$ catalyst has a higher surface area compared to 10\%Ag@ZnO NWs (see Table 1), the 10\%Ag@ZnO NW catalyst obtained higher hydrogen production. In fact, the amount of hydrogen obtained by the unmodified $\mathrm{ZnO}$ NWs was not expected and it is unusual for $\mathrm{ZnO}$. Zhang et al. [43] have reported that one-dimensional nanostructures, such as nanowires, may have greater photocatalytic activity due to their large surface-to-volume ratio, as compared to other morphologies. Additionally, different studies [43-45] reveal that surface properties such as surface defects and oxygen vacancies of photocatalysts play a significant role in photocatalytic activity. These studies argue that the crystalline defects of $\mathrm{ZnO}$ nanowires exist primarily due to oxygen vacancies and that nanoparticles with crystalline defects can exhibit visible light photocatalysis even without doping with transitional metals. 
At $320 \mathrm{~nm}$ (UV light), direct photoexcitation of $\mathrm{TiO}_{2}$ or $\mathrm{ZnO}$ with photons of energy greater than the bandgap $(\lambda<380 \mathrm{~nm})$ is assumed, leading to the generation of electrons in the semiconductor conduction band and electron holes in the valence band [46]. The electrons in the conduction band will move to the silver nanoparticles, acting as electron buffers and catalytic sites for hydrogen generation [46]. The electron holes will be quenched by the sacrificial electron donors $\left(\mathrm{SO}_{3}{ }^{2-} / \mathrm{SO}_{4}{ }^{2-}\right)[23,24]$.

At $400 \mathrm{~nm}$, the highest hydrogen production values were $1065,963,648$, and $516 \mu \mathrm{mol} / \mathrm{hg}$, obtained by 10\%Ag@TiO 2 NWs, 10\%Ag@ZnO NWs, 10\%Ag@TiO 2 -P25, and 10\%Ag@ZnO commercial, respectively (Figure 7B). The highest difference in hydrogen production between silver-based and unmodified catalysts was obtained by the $10 \% \mathrm{Ag} @ \mathrm{TiO}_{2} \mathrm{NWs}$ and bare $\mathrm{TiO}_{2} \mathrm{NWs}(990 \mu \mathrm{mol} / \mathrm{hg})$. This amount was 14 times higher than that reported by the pristine catalyst. Details of the other maximum amounts and differences can be found in Table 3.

Table 3. Silver-based catalysts with the highest hydrogen production and their difference from the unmodified supports at a wavelength of $400 \mathrm{~nm}$ *.

\begin{tabular}{|c|c|c|c|c|}
\hline Catalyst & $\begin{array}{c}\text { Maximum } \mathrm{H}_{2} \\
\text { Production; } \\
\text { Silver-Based Catalysts } \\
(\mu \mathrm{mol} / \mathrm{gh})\end{array}$ & $\begin{array}{c}\text { Maximum } \mathrm{H}_{2} \\
\text { Production } \\
\text { Unmodified Catalyst } \\
(\mu \mathrm{mol} / \mathrm{gh})\end{array}$ & $\begin{array}{c}\text { Difference in } \mathrm{H}_{2} \\
\text { Production }(\mu \mathrm{mol} / \mathrm{gh})\end{array}$ & $\begin{array}{l}\text { Times Greater Than } \\
\text { Unmodified Catalyst }\end{array}$ \\
\hline $10 \% \mathrm{AgTiO}_{2} \mathrm{NWs}$ & 1065 & $\mathrm{TiO}_{2}$ NWs; 75 & 990 & 14.20 \\
\hline $10 \% \mathrm{AgTiO}_{2}-\mathrm{P} 25$ & 648 & $\mathrm{TiO}_{2}-\mathrm{P} 25 ; 71$ & 577 & 9.13 \\
\hline $10 \% A g Z n O ~ N W s$ & 963 & ZnO NWs; 427 & 430 & 2.26 \\
\hline $10 \% \mathrm{AgZnO}$ comm. ** & 516 & $\mathrm{ZnO}$ Comm * 45 & 471 & 11.47 \\
\hline
\end{tabular}

* Only the highest hydrogen production from all the silver-based catalysts is shown, ${ }^{* *}$ Commercial.

As it was seen at $320 \mathrm{~nm}$, the highest hydrogen production at $400 \mathrm{~nm}$ was obtained with the catalysts of $10 \mathrm{wt} . \%$ of silver loadings and higher surface areas. This is an indication that it could be possible to increase the amount of hydrogen at higher silver loadings. At 400 nm, the Ag@ $@ \mathrm{TiO}_{2} \mathrm{NW}$ catalysts produced more hydrogen than the Ag@ZnO NW composites. This could be attributed to the marked difference in surface area between the catalysts (see Table 1 ) and the band gap energies of the supports. $\mathrm{ZnO}$ has a bandgap energy of $3.37 \mathrm{eV}$, while for $\mathrm{TiO}_{2}$, the bandgap is somewhat lower (3.2 eV, anatase); therefore, with a wavelength of $400 \mathrm{~nm}$, it would be easier to promote the excitation of the electrons in the valence band of $\mathrm{TiO}_{2}$ than those of $\mathrm{ZnO}$ [42].

It is assumed that when irradiated with visible light $(\lambda>400 \mathrm{~nm})$, photoexcitation of Ag NPs due to plasmon resonance occurs, and electrons from Ag are injected into the $\mathrm{TiO}_{2}$ or $\mathrm{ZnO}$ conduction band, leading to the generation of holes in the Ag NPs [46]. The water molecule gains the electrons in the conduction band and hydrogen is produced.

At $500 \mathrm{~nm}$, the catalysts with a silver loading of $10 \%$ by weight (see Figure $7 \mathrm{C}$ ) obtained their highest hydrogen production, as seen at other irradiation wavelengths. The

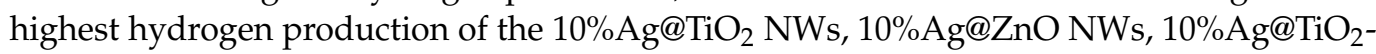
P25, and 10\%Ag@ZnO commercial was 1119, 921, 653, and $466 \mu \mathrm{mol} / \mathrm{hg}$, respectively, representing an increase in hydrogen production of ca. 18, 2, 36, and 12 times compared to the bare $\mathrm{TiO}_{2} \mathrm{NWs}, \mathrm{ZnO} N W s, \mathrm{TiO}_{2}-\mathrm{P} 25$, and $\mathrm{ZnO}$ commercial catalysts, respectively (see Table 4). Furthermore, as seen at other wavelengths, the larger the surface area, the greater the hydrogen production. This is an indication of the synergism between the deposited Ag NPs and the surface area of the catalysts. As previously mentioned, at wavelengths above $400 \mathrm{~nm}(\lambda>400 \mathrm{~nm})$, the hydrogen production will depend mainly on the Ag NPs and their ability to inject photoexcited electrons into the conduction band of semiconductors.

Table 5 shows recent research on photocatalytic hydrogen production using silverbased catalysts ( $\mathrm{Ag} @ \mathrm{TiO}_{2}$ and $\left.\mathrm{Ag} @ \mathrm{ZnO}\right)$. These investigations consider different parameters such as Ag loading, crystalline structure, morphology of the support and nanoparticles, reaction mixture, and reaction time, among others, when experiments are carried out. 
Considering the previous scientific literature (see Table 5), the catalysts synthesized in this research gave rise to the highest hydrogen production values achieved by water splitting. However, it is important to note that the experimental parameters used in the literature were not exactly the same as those used in this research.

Table 4. Silver-based catalysts with the highest hydrogen production and their difference from the unmodified supports at a wavelength of $500 \mathrm{~nm}^{*}$.

\begin{tabular}{|c|c|c|c|c|}
\hline Catalyst & $\begin{array}{c}\text { Maximum } \mathrm{H}_{2} \\
\text { Production } \\
\text { Silver-Based Catalysts } \\
(\mu \mathrm{mol} / \mathrm{gh})\end{array}$ & $\begin{array}{c}\text { Maximum } \mathrm{H}_{2} \\
\text { Production } \\
\text { Unmodified Catalyst } \\
(\mu \mathrm{mol} / \mathrm{gh})\end{array}$ & $\begin{array}{c}\text { Difference in } \mathrm{H}_{2} \\
\text { Production }(\mu \mathrm{mol} / \mathrm{gh})\end{array}$ & $\begin{array}{l}\text { Times Greater Than } \\
\text { Unmodified Catalyst }\end{array}$ \\
\hline $10 \% \mathrm{AgTiO}_{2} \mathrm{NWs}$ & 1119 & $\mathrm{TiO}_{2} \mathrm{NWs} ; 62$ & 1057 & 18.05 \\
\hline $10 \% \mathrm{AgTiO}_{2}-\mathrm{P} 25$ & 653 & $\mathrm{TiO}_{2}-\mathrm{P} 25 ; 18$ & 635 & 36.28 \\
\hline $10 \% A g Z n O N W s$ & 921 & ZnO NWs; 349 & 572 & 2.64 \\
\hline $10 \% \mathrm{AgZnO}$ comm. ** & 466 & $\mathrm{ZnO}$ Comm *; 38 & 428 & 12.26 \\
\hline
\end{tabular}

* Only the highest hydrogen production from all the silver-based catalysts is shown, ${ }^{* *}$ Commercial.

Table 5. Recent works for photocatalytic hydrogen production using Ag@ $\mathrm{TiO}_{2}$ and $\mathrm{Ag} @ \mathrm{ZnO}$ catalysts.

\begin{tabular}{|c|c|c|c|c|c|c|}
\hline Reference & $\begin{array}{c}\mathrm{H}_{2} \text { Production } \\
(\mu \mathrm{mol})\end{array}$ & Source (nm) & $\begin{array}{l}\text { Irradiation } \\
\text { Time (h) }\end{array}$ & $\begin{array}{c}\mathrm{TiO}_{2} \text { or } \mathrm{ZnO} \\
\text { Crystal Structure * }\end{array}$ & Reaction Mixture & $\operatorname{Ag}(w t . \%)$ \\
\hline$[12]$ & 910 & $\lambda>400$ & 2 & $\mathrm{TiO}_{2} ; \mathrm{A}$ & Water: Methanol & 14 \\
\hline [47] & 90 & $\lambda=457$ & 8 & $\mathrm{TiO}_{2} ; \mathrm{A}$ & Water: $0.1 \mathrm{M} \mathrm{Na}_{2} \mathrm{~S}$ & 2 \\
\hline [15] & 443.6 & $\lambda>400$ & 4 & $\mathrm{ZnO} ; \mathrm{W}$ & $\begin{array}{c}\text { Water: } 0.25 \mathrm{M} \mathrm{Na}_{2} \mathrm{~S} \\
0.35 \mathrm{M} \mathrm{Na}_{2} \mathrm{SO}_{3}\end{array}$ & 3.12 \\
\hline [16] & 55 & $\lambda>400$ & 8 & $\mathrm{ZnO} ; \mathrm{W}$ & $\begin{array}{l}\text { Water: } 3.0 \mathrm{~g} \mathrm{Na}_{2} \mathrm{~S}, 2.2 \\
\mathrm{~g} \mathrm{Na}_{2} \mathrm{SO}_{3}\end{array}$ & 0.5 \\
\hline This work & 1119 & $\lambda=500$ & 2 & $\mathrm{TiO}_{2}$ NWs; R & $\begin{array}{l}\text { Water: } 0.5 \mathrm{M} \mathrm{Na}_{2} \mathrm{~S}, \\
0.03 \mathrm{M} \mathrm{Na}_{2} \mathrm{SO}_{3}\end{array}$ & 10 \\
\hline This work & 653 & $\lambda=500$ & 2 & $\mathrm{TiO}_{2}-\mathrm{P} 25 ; \mathrm{A}, \mathrm{R}$ & $\begin{array}{c}\text { Water: } 0.5 \mathrm{M} \mathrm{Na}_{2} \mathrm{~S} \text {, } \\
0.03 \mathrm{M} \mathrm{Na}_{2} \mathrm{SO}_{3}\end{array}$ & 10 \\
\hline This work & 963 & $\lambda=400$ & 2 & ZnO NWs; W & $\begin{array}{c}\text { Water: } 0.5 \mathrm{M} \mathrm{Na}_{2} \mathrm{~S} \text {, } \\
0.03 \mathrm{M} \mathrm{Na}_{2} \mathrm{SO}_{3}\end{array}$ & 10 \\
\hline This work & 516 & $\lambda=400$ & 2 & $\mathrm{ZnO}$ comm. ${ }^{* *} \mathrm{~W}$ & $\begin{array}{c}\text { Water: } 0.5 \mathrm{M} \mathrm{Na}_{2} \mathrm{~S} \\
0.03 \mathrm{M} \mathrm{Na}_{2} \mathrm{SO}_{3}\end{array}$ & 10 \\
\hline
\end{tabular}

${ }^{*} \mathrm{~A}=$ anatase, $\mathrm{R}=$ rutile, $\mathrm{W}=$ wurtzite $^{* *}$ commercial.

\subsection{Photocatalytic Degradation of Ciprofloxacin}

The photocatalytic activity of the silver-based catalysts was also studied by the degradation of the antibiotic ciprofloxacin (see Figure 8 and Table 6). The incorporation of Ag NPs increased the percentage of degradation in comparison with the unmodified catalysts. The superior performance of the silver-based catalysts is attributed to the combination of its smaller bandgap and plasmonic effects, which allow visible light energy harvesting and improved charge carrier lifetimes [12]. For the $\mathrm{Ag} @ \mathrm{TiO}_{2}-\mathrm{P} 25$ system (Figure 8A), the higher degradation was obtained with $5 \% \mathrm{Ag} @ \mathrm{TiO}_{2}-\mathrm{P} 25$. However, it should be noted that with $3 \% \mathrm{Ag} @ \mathrm{TiO}_{2}-\mathrm{P} 25$, the degradation obtained was only $3 \%$ below the maximum, which means that there is no significant difference between 3\%Ag@ $\mathrm{TiO}_{2}-\mathrm{P} 25$ and 5\%Ag@ $@ \mathrm{TiO}_{2-}$ $\mathrm{P} 25$. In addition, $10 \% \mathrm{Ag} @ \mathrm{TiO}_{2}-\mathrm{P} 25$ degraded approximately $70 \%$ of the ciprofloxacin within the first $10 \mathrm{~min}$ of the reaction. After that time, less than $15 \%$ degradation was observed, possibly due to the lack of active sites on the catalyst's surface [48]. Moreover, $3 \% \mathrm{Ag} @ \mathrm{TiO}_{2}-\mathrm{P} 25$ showed ca. 85\% degradation after $40 \mathrm{~min}$ of reaction and increased to only $87 \%$ at $60 \mathrm{~min}$. According to these results, the water treatment could be stopped at 
40 min. After this reaction time, 10\% $\mathrm{Ag} @ \mathrm{TiO}_{2}-\mathrm{P} 25$ did not show a significant increase in degradation, which could indicate that a saturation point was reached.

Table 6. Degradation percentages of all silver-based catalysts after $60 \mathrm{~min}$ of reaction.

\begin{tabular}{ccccc}
\hline Ag Loading (wt.\%) & $\mathrm{TiO}_{\mathbf{2}}$ NWs (\%) & $\mathbf{T i O}_{\mathbf{2}}$-P25 (\%) & ZnO NWs (\%) & $\begin{array}{c}\text { ZnO Commercial } \\
\text { (\%) }\end{array}$ \\
\hline 0 & 69.12 & 71.36 & 68.26 & 94.83 \\
1 & 76.11 & 80.11 & 73.37 & 95.60 \\
3 & 83.09 & 87.09 & 78.26 & 99.72 \\
5 & 85.92 & 89.92 & 71.11 & 98.39 \\
10 & 81.26 & 82.26 & 70.65 & 92.31 \\
\hline
\end{tabular}

The Ag@ $\mathrm{TiO}_{2} \mathrm{NW}$ system (Figure 8B) yielded similar results to those mentioned above. The highest degradation percentage, 86\%, was obtained with 5\%Ag@ $\mathrm{TiO}_{2} \mathrm{NWs}$ and showed a continuous degradation pattern, suggesting that there is no saturation point. Similar results have been reported by other authors [19]. Although all the Ag@TiO ${ }_{2} \mathrm{NWs}$ catalysts have a higher surface area than $\mathrm{Ag} @ \mathrm{TiO}_{2}-\mathrm{P} 25$, the degradation percentages were better for $\mathrm{Ag} @ \mathrm{TiO}_{2}-\mathrm{P} 25$ catalysts. Some authors [49] have reported similar results and have justified them as due mainly to the crystalline structure of the catalysts and not so much to the surface area, since it is well known that anatase exhibits better photocatalytic performance than the rutile-type structure. In this regard, $\mathrm{TiO}_{2}-\mathrm{P} 25$ is composed of $70 \%$ anatase and $30 \%$ rutile, while $\mathrm{TiO}_{2} \mathrm{NWs}$ are $100 \%$ rutile (see Figure $3 \mathrm{~A}$ ).

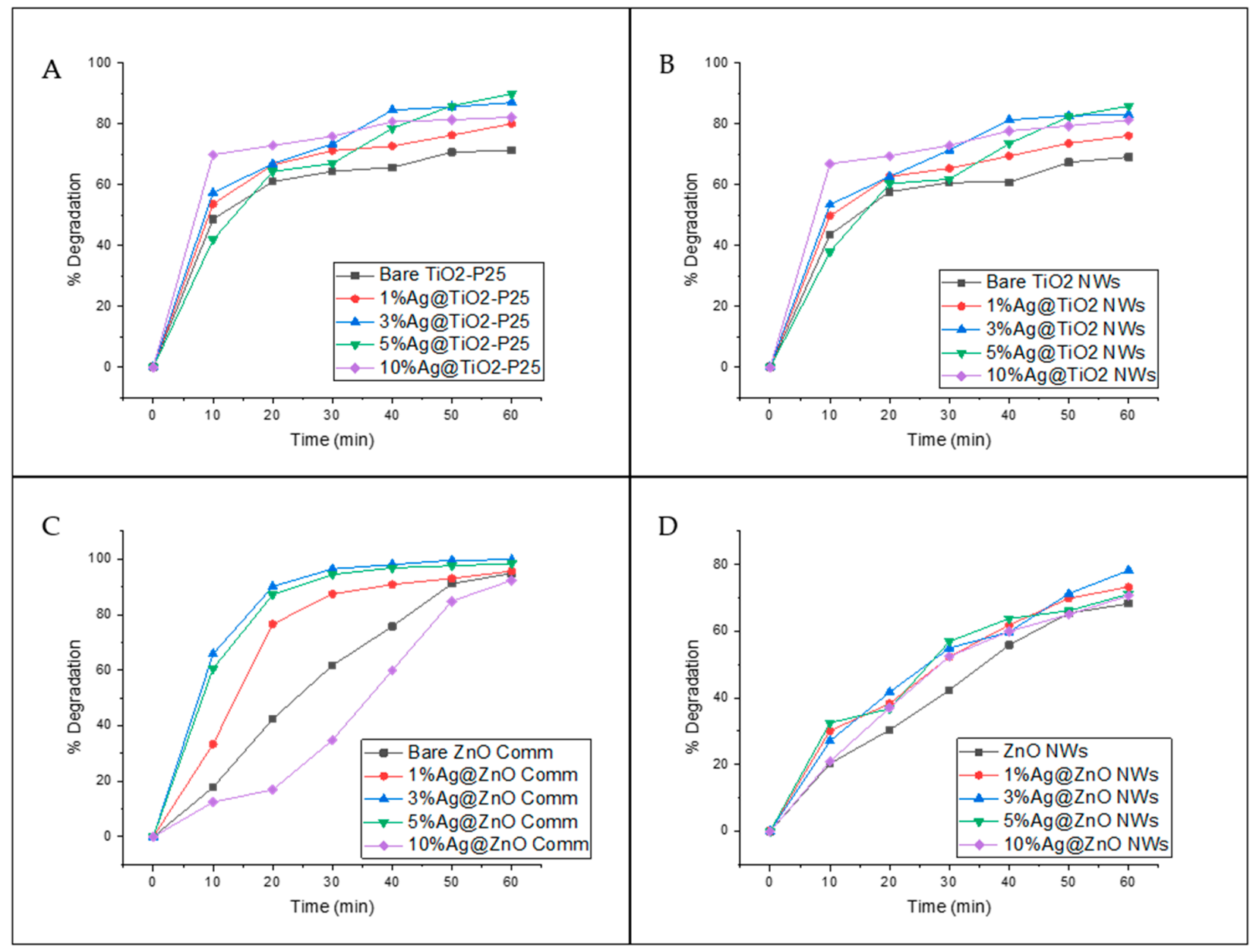

Figure 8. Percentage of degradation of ciprofloxacin using Ag@ $\mathrm{TiO}_{2}-\mathrm{P} 25$ (A), Ag@ $\mathrm{TiO}_{2} \mathrm{NW}(\mathbf{B}), \mathrm{Ag} @ \mathrm{ZnO}$ commercial (C), and Ag@ZnO NW (D) catalysts. 
The Ag@ZnO commercial catalysts (bare ZnO commercial, 1\%Ag@ZnO commercial, and 10\%Ag@ZnO commercial) showed minor efficiency during the first $10 \mathrm{~min}$ of reaction (see Figure 8C). However, after completing the $60 \mathrm{~min}$ of reaction, they showed better performance compared to $\mathrm{TiO}_{2}$ catalysts. This behavior could be attributed to $\mathrm{pH}$, since $\mathrm{TiO}_{2}$ works better in an acidic environment due to the zero-point charge of this material [50]. With 3\%Ag@ZnO commercial, 90\% degradation was achieved only after 20 min of reaction. No significant difference was observed between 3\%Ag@ZnO commercial and 5\%Ag@ZnO commercial catalysts. Moreover, these samples degrade $+60 \%$ of the ciprofloxacin in the first $10 \mathrm{~min}$ of reaction, while the bare $\mathrm{ZnO}$ took $30 \mathrm{~min}$ to reach this point, clearly indicating that the best performance is achieved when the material is doped with Ag.

Ag@ZnO NW (Figure 8D) catalysts showed lower efficiency compared to the commercial catalyst. All catalysts showed a constant increase over time, suggesting that the catalyst still has active sites available, even after 60 min of reaction, and no saturation point is expected to occur. The highest degradation percentage (ca. 78\%) was obtained with 3\%Ag@ZnO NWs.

In the case of $\mathrm{ZnO}$ commercial and $\mathrm{ZnO} \mathrm{NWs}$, both exhibited the same wurtzite crystalline phase (see Figure 3C,D) but demonstrated a significant difference in degradation percentages. These differences are attributed to the agglomeration of particles; the $\mathrm{ZnO}$ commercial consists of a finer powder compared to the as-synthesized material. This might cause agglomeration of the as-synthesized catalyst, enhancing the catalyst-catalyst contact instead of the catalyst-antibiotic contact, reducing the degradation efficiency of the system.

To further study the photocatalytic activity of the silver-based catalysts, control experiments and stability tests were conducted for the two catalysts with the highest percentage of degradation (5\%Ag@ $\mathrm{TiO}_{2}-\mathrm{P} 25,3 \% \mathrm{Ag} @ \mathrm{ZnO}$ commercial) (Figure 9). The control experiments for both catalysts were similar (see Figure 9A,B). After 60 min of reaction, it was observed that ciprofloxacin is highly recalcitrant and stable under normal or environmental conditions. This is evidenced by the fact that no degradation or significant changes in ciprofloxacin concentration are observed over time without the catalyst or radiation source. From the control experiments, it is shown that photocatalysis is the primary degradation route; this means that neither catalysis nor photolysis are enough to degrade the contaminant. Instead, degradation occurs due to a synergistic effect between the catalyst and the radiation source.

The stability tests (Figure 9C,D) for both catalysts were also very similar. The results showed that even after 60 min of reaction, the catalysts were demonstrated to be highly stable and that no significant chemical change occurred that endangered the efficiency of the materials. After seven cycles, the degradation efficiency decreased by $\sim 7 \%$, which can be estimated as $1 \%$ per cycle of use. This rough estimate suggests that these catalysts could be employed for several more cycles without the need for resynthesizing. This means that these materials could decrease the environmental remediation costs if used in contaminated settings.

The results obtained have made it possible to establish the possible mechanisms involved in the two processes studied in this research. Figure 10 shows a possible mechanism for the production of hydrogen via water splitting using $\mathrm{Ag} @ \mathrm{TiO}_{2}$ or $\mathrm{Ag} @ \mathrm{ZnO}$ catalysts under visible and ultraviolet light. When irradiated with ultraviolet light (Figure 10A), direct photoexcitation of $\mathrm{TiO}_{2}$ or $\mathrm{ZnO}$ with photons with energy larger than the bandgap $(\lambda<380 \mathrm{~nm})$ is assumed, leading to the generation of electrons in the semiconductor conduction band and electron holes in the valence band [46]. The electron in the conduction band will move to the silver nanoparticles, acting as electron buffers and catalytic sites for hydrogen generation [11,12]. The electron holes will be quenched by the sacrificial electron donors $\left(\mathrm{SO}_{3}{ }^{2-} / \mathrm{SO}_{4}{ }^{2-}\right)$. When irradiated with visible light $(\lambda>400 \mathrm{~nm})$ (Figure 10B), photoexcitation of Ag NPs occurs and electrons from the Ag are injected into the $\mathrm{TiO}_{2}$ or $\mathrm{ZnO}$ conduction band, leading to the generation of holes in the Ag NPs and electrons in the $\mathrm{TiO}_{2}$ or $\mathrm{ZnO}$ conduction band $[11,12,46]$. The water molecule gains the electrons in the conduction band and hydrogen is produced. Holes in the Ag NPs will be quenched by 
the sacrificial electron donors $\left(\mathrm{SO}_{3}{ }^{2-} / \mathrm{SO}_{4}{ }^{2-}\right)$. This proposed mechanism is an oversimplification since different studies [11-13] have determined that, due to the silver/titania or silver/zinc oxide interfacial contact, the conduction band of the semiconductor undergoes a shift toward more negative potentials. Thus, the charge distribution between the Ag NPs and the semiconductor causes a shift in the Fermi level toward more negative potentials [13].

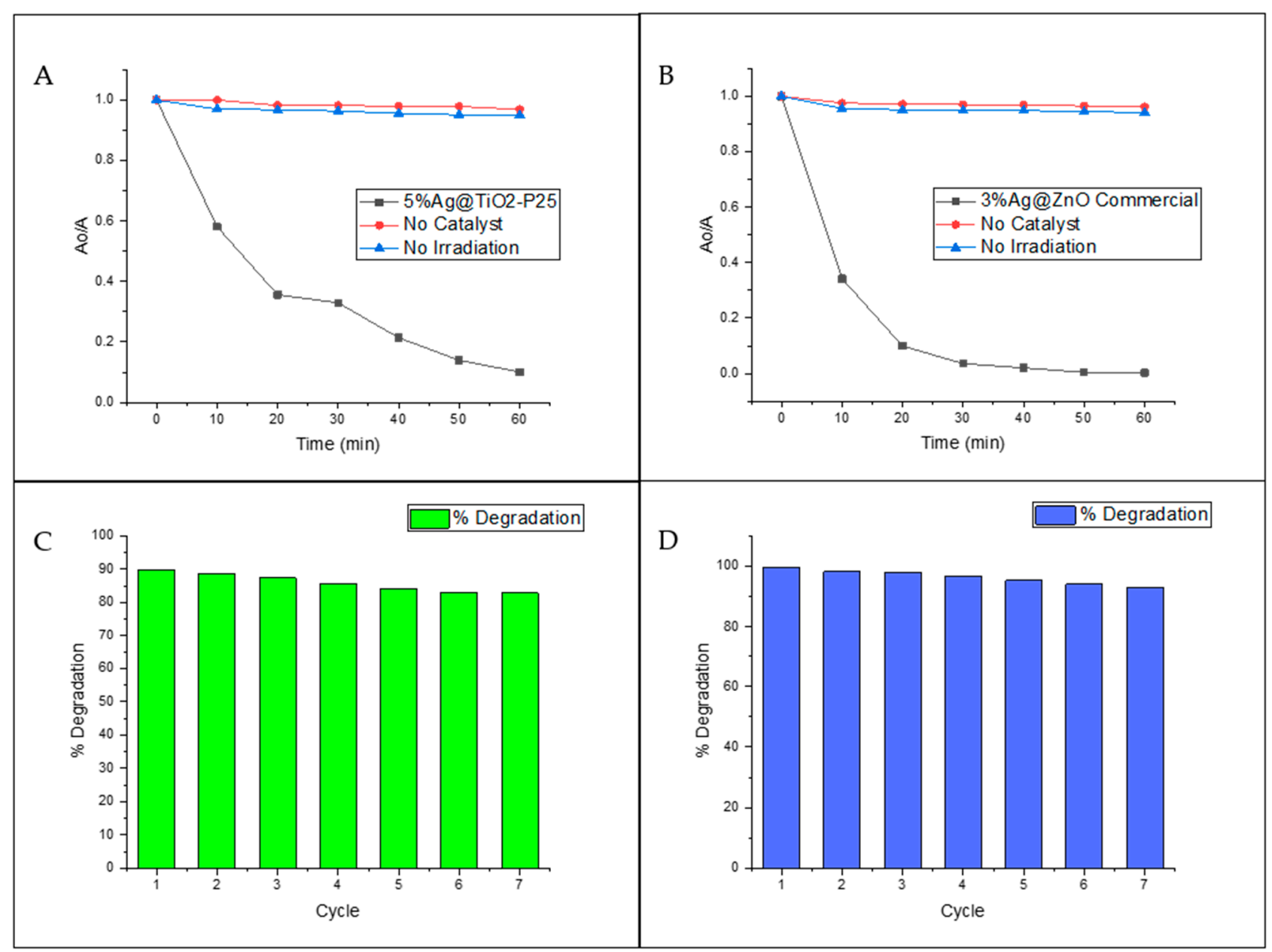

Figure 9. Control experiments and stability tests for the 5\%Ag@ $\mathrm{TiO}_{2}-\mathrm{P} 25(\mathbf{A}, \mathbf{C})$ and $3 \% \mathrm{Ag} @ \mathrm{ZnO}$ commercial (B,D) catalysts.

The mechanism for the degradation of ciprofloxacin using the silver-based catalysts is shown in Figure 11. Under ultraviolet light (Figure 11A), electrons from the valence band of $\mathrm{TiO}_{2}$ or $\mathrm{ZnO}$ migrate to the conduction band of the semiconductors and holes in the valence band are formed. The electrons in the conduction band move to the Ag NPs, acting as an electron buffer, and these electrons may react with adsorbed molecular oxygen to generate superoxide anions, which in turn can react with water molecules to form hydroxyl radicals. These free radicals are very efficient in the photodegradation of organic pollutants such as ciprofloxacin [12]. The holes formed in the valence band of the semiconductors then will promote the oxidation of ciprofloxacin and therefore lead to degradation. When irradiated with visible light (Figure 11B), Ag NPs form an interface with semiconducting materials and a Schottky barrier is formed, resulting in a new Fermi level and a high number of electrons due to the presence of metallic Ag [12]. Additionally, free electrons are stimulated through the silver surface plasmon resonance mechanism and can move into the conduction band of the partially reduced $\mathrm{TiO}_{2}$ or $\mathrm{ZnO}$ [12]. These conduction band electrons may react with adsorbed molecular oxygen to generate superoxide anions, then react with water molecules and form hydroxyl radicals that will eventually oxidize the ciprofloxacin. 
In future research, already under development, the different intermediate compounds generated during the ciprofloxacin degradation process will be analyzed, which will allow us to establish the catalytic photodegradation mechanisms that, eventually, will allow the process to be improved.

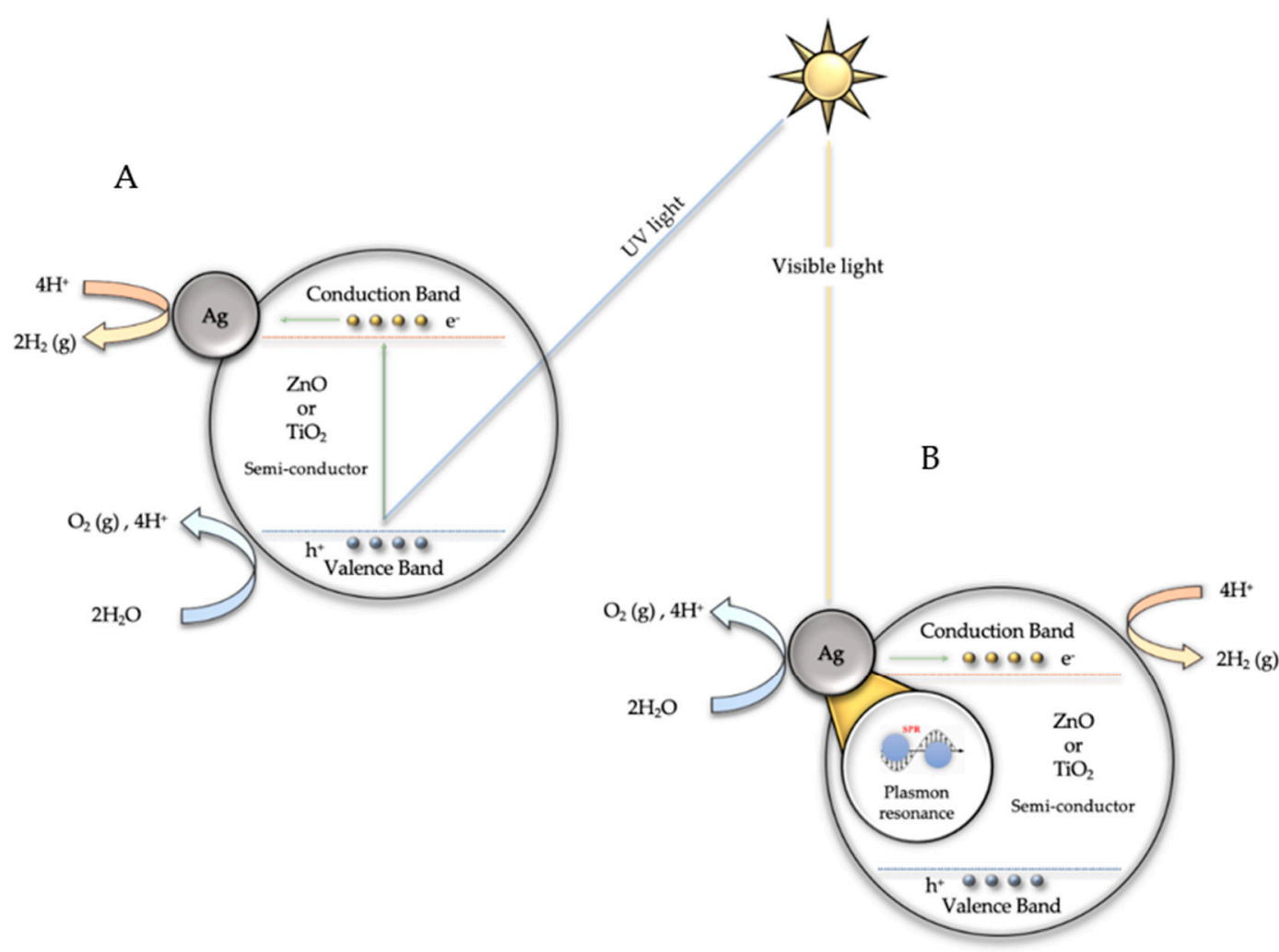

Figure 10. Mechanism for the production of hydrogen via water splitting using Ag@ $\mathrm{TiO}_{2}$ or Ag@ZnO catalysts under ultraviolet (A) and visible light (B).

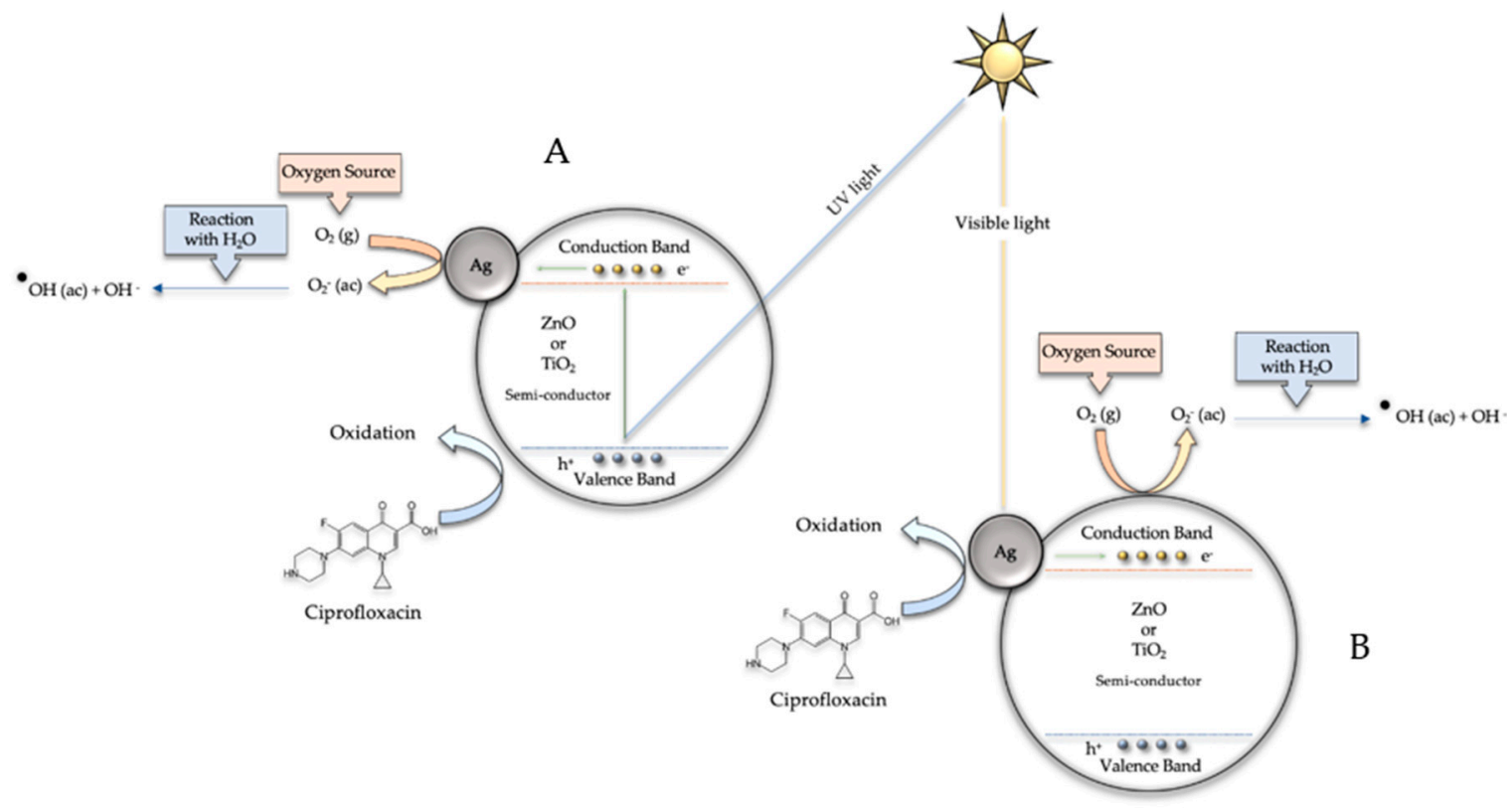

Figure 11. Mechanism for the degradation of ciprofloxacin using the silver-based catalysts under ultraviolet (A) and visible light (B). 


\section{Conclusions}

Silver-based catalysts were synthesized to study their ability to mimic natural processes such as the splitting of water and the degradation of pollutants. The photocatalytic activity of the composites was studied by the production of hydrogen via water splitting using UV-vis light and the degradation of the antibiotic ciprofloxacin.

The catalyst with the highest hydrogen production was 10\%Ag@TiO $2 \mathrm{NW}(1119 \mu \mathrm{mol} / \mathrm{hg})$, being 18 times greater than the amount obtained with the pristine $\mathrm{TiO}_{2} \mathrm{NW}$ catalyst. The most dramatic difference in hydrogen production was obtained with $10 \% \mathrm{Ag} @ \mathrm{TiO}_{2}-\mathrm{P} 25$ $(635 \mu \mathrm{mol} / \mathrm{hg})$, being 36 times greater than the amount reported for the unmodified $\mathrm{TiO}_{2-}$ P25 $(18 \mu \mathrm{mol} / \mathrm{hg})$. The enhancement of the catalytic activity is attributed to a synergism between the silver nanoparticles incorporated and the high surface area of the composites.

In the case of the degradation of ciprofloxacin, all the silver-based catalysts degraded more than $70 \%$ of the antibiotic in $60 \mathrm{~min}$. The catalyst that exhibited the best result was $3 \% \mathrm{Ag} @ \mathrm{ZnO}$ commercial with $99.72 \%$ of degradation. The control experiments and stability tests showed that photocatalysis was the route of degradation and the selected silver-based catalysts were stable after seven cycles, with less than $1 \%$ loss of efficiency per cycle. These results suggest that the catalysts could be employed in several more cycles without the need for resynthesizing, thus reducing remediation costs.

The results obtained in this research introduce an immense field of possibilities for the development of high-performance photocatalysts. The systems studied have proven to be very active in the production of hydrogen and in the degradation of ciprofloxacin, so perhaps it is towards the development of multi-application systems that we will have to redouble our efforts in the future.

Author Contributions: Conceptualization, A.M., F.M., L.S.-V.; methodology, A.M.; formal analysis, A.M., F.M., L.S.-V.; investigation, A.M., C.C.-C., C.A.V.-C., G.J.C.-S., K.F., L.S.-V., E.R., C.M.; resources, F.M., C.M., F.I.P.; writing—original draft preparation, A.M.; writing-review and editing, A.M., F.M., L.S.-V.; supervision, A.M., F.M.; project administration, A.M., F.M.; funding acquisition, F.M., C.M., F.I.P. All authors have read and agreed to the published version of the manuscript.

Funding: Financial support provided by the US DoE, through the Massie Chair project at University of Turabo, US Department of Defense, under contract W911NF-14-1-0046, from the Ministerio de Economía y Competitividad (MINECO) of Spain, through the grant ENE2014-57977-C2-1-R, and from NSF Center for the Advancement of Wearable Technologies-CAWT (Grant 1849243) are gratefully acknowledged.

Institutional Review Board Statement: Not applicable.

Informed Consent Statement: Not applicable.

Data Availability Statement: Not applicable.

Acknowledgments: Technical assistance of I. Poveda from "Servicio Interdepartamental de Investigacion, SIdI" at UAM, is gratefully acknowledged. The facilities provided by the National Center for Electron Microscopy at Complutense University of Madrid (Spain) and the Materials Characterization Center at University of Puerto Rico are gratefully acknowledged.

Conflicts of Interest: The authors declare no conflict of interest.

\section{References}

1. Zafar, M.W.; Shahbaz, M.; Hou, F.; Sinha, A. From Nonrenewable to Renewable Energy and Its Impact on Economic Growth: The role of Research and Development Expenditures in Asia-Pacific Economic Cooperation Countries. J. Clean. Prod. 2018, 212, 1166-1178. [CrossRef]

2. Skovgaard, J.; van Asselt, H. The politics of fossil fuel subsidies and their reform: Implications for climate change mitigation. Wiley Interdiscip. Rev. Clim. Chang. 2019, 10, 1-12. [CrossRef]

3. Zhang, H.; Carey, A.M.; Jeon, K.W.; Liu, M.; Murrell, T.D.; Locsin, J.; Lin, S.; Yan, H.; Woodbury, N.; Seo, D.K. Highly Stable and Scalable Photosynthetic Reaction Center-Graphene Hybrids Electrode System for Biomimetic Solar Energy Transduction. J. Mater. Chem. A 2017, 5, 6038-6041. [CrossRef] 
4. Martín-Palma, R.J.; Lakhtakia, A. Progress on bioinspired, biomimetic, and bioreplication routes to harvest solar energy. App. Phys. Rev. 2017, 4, 1-7. [CrossRef]

5. Ye, S.; Ding, C.; Chen, R.; Fan, F.; Fu, P.; Yin, H.; Wang, X.; Wang, Z.; Du, P.; Li, C. Mimicking the Key functions of Photosystem II in Artificial Photosynthesis for Photoelectrocatalytic Water Splitting. J. Am. Chem. Soc. 2018, 140, 3250-3256. [CrossRef]

6. Ye, S.; Ding, C.; Liu, M.; Wang, A.; Huang, Q.; Li, C. Water Oxidation for Artificial Photosynthesis. Adv. Mater. 2019, $31,1-33$. [CrossRef]

7. Li, Q.; Xia, Y.; Yang, C.; Lv, K.; Lei, M.; Li, M. Building a direct Z-scheme heterojunction photocatalyst by Znln $\mathrm{S}_{4} \mathrm{~S}_{4}$ nanosheets and $\mathrm{TiO}_{2}$ hollowspheres for highly-efficient artificial photosynthesis. Chem. Eng. J. 2018, 349, 287-296. [CrossRef]

8. Ji, Y.; Luo, Y. Direct Dontation of Proton from $\mathrm{H}_{2} \mathrm{O}$ to $\mathrm{CO}_{2}$ in Artificial Photosynhtesis on the Anatase TiO 2 (101) Surface. J. Phys. Chem. 2019, 123, 3019-3023. [CrossRef]

9. Wang, X.; Li, Q.; Zhou, C.; Cao, Z.; Zhang, R. ZnO Rod/Reduced Graphene Oxide Sensitized by $\alpha$-Fe ${ }_{2} \mathrm{O}_{3}$ nanoparticles for effective visible-light photoreduction of $\mathrm{CO}_{2}$. J. Colloid Interface Sci. 2019, 554, 335-343. [CrossRef]

10. Liang, S.; Han, B.; Liu, X.; Chen, W.; Peng, M.; Guan, G.; Deng, H.; Lin, Z. 3D spatially branched hierarchical Z-scheme CdS-Au nanoclusters-ZnO hybrids with boosted photocatalytic hydrogen evolution. J. Alloys Compd. 2018, 754, 105-113. [CrossRef]

11. Geng, R.; Yin, J.; Zhou, J.; Jiao, T.; Feng, Y.; Zhang, L.; Chen, Y.; Bai, Z.; Peng, Q. In Situ Construction of $\mathrm{Ag}_{\mathrm{T}} \mathrm{TiO}_{2} / \mathrm{g}-\mathrm{C}_{3} \mathrm{~N}_{4}$ Heterojunction Nanocomposite Based on Hierarchical Co-Assembly with Sustainable Hydrogen Evolution. Nanomaterials 2020, 10, 1. [CrossRef] [PubMed]

12. Saravanan, R.; Manoj, D.; Qin, J.; Naushad, M.; Gracia, F.; Lee, A.F.; Khan, M.M.; Gracia-Pinilla, M. Mechanothermal synthesis of $\mathrm{Ag} / \mathrm{TiO}_{2}$ for photocatalytic Methyl Orange degradation and hydrogen production. Process Saf. Environ. Prot. 2018, 120, 339-347. [CrossRef]

13. Zhang, Y.; Fu, Y.; Zhang, D.; Chen, Y. One-Step Synthesis of Ag@TiO 2 Nanoparticles for Enhanced Photocatalytic Performance. Nanomaterials 2018, 8, 32. [CrossRef] [PubMed]

14. Mao, H.; Fei, Z.; Bian, C.; Yu, L.; Chen, S.; Qian, Y. Facile synthesis of high-performance photocatalysts based on $\mathrm{Ag}_{\mathrm{g}} / \mathrm{TiO}{ }_{2}$ composites. Ceram. Int. 2019, 45, 12586-12589. [CrossRef]

15. Mou, H.; Song, C.; Zhou, Y.; Zhang, B.; Wang, D. Design and synthesis of porous Ag/ZnO nanosheets assemblies as super photocatalysts for enhanced visible-light degradation of 4-nitrophenol and hydrogen evolution. Appl. Catal. B 2018, 221, 565-573. [CrossRef]

16. Xin, Z.; Li, L.; Zhang, X.; Zhang, W. Microwave-assisted hydrothermal synthesis of chrysanthemum-like Ag/ZnO prismatic nanorods and their photocatalytic properties with multiple modes for dye degradation and hydrogen production. RSC Adv. 2018, 8, 6027-6038. [CrossRef]

17. Liu, H.; Liu, H.; Yang, J.; Zhai, H.; Liu, X.; Jia, H. Microwave-assisted one-pot synthesis of Ag decorated flower-like ZnO composites photocatalysts for dye degradation and NO removal. Ceram. Int. 2019, 45, 20133-20140. [CrossRef]

18. Trang, T.N.Q.; Phan, T.B.; Nam, N.D.; Thu, V.T.H. In situ charge transfer at the Ag@ZnO photoelectrochemical interface toward the high photocatalytic performance of $\mathrm{H}_{2}$ evolution and RhB degradation. ACS Appl. Mater. Interfaces 2020, 12, 12195-122206. [CrossRef]

19. Malakootian, M.; Nasiri, A.; Amiri Gharaghani, M. Photocatalytic degradation of ciprofloxacin antibiotic by $\mathrm{TiO}_{2}$ nanoparticles immobilized on a glass plate. Chem. Eng. Commun. 2019, 207, 1-17. [CrossRef]

20. Cotto, M.; Campo, T.; Elizalde, E.; Gómez, A.; Morant, C.; Márquez, F. Photocatalytic degradation of rhodamine-B under UV-visible light irradiation using different nanostructured catalyst. Am. Chem. Sci. J. 2013, 3, 178-202. [CrossRef]

21. Lin, C.C.; Li, Y.Y. Synthesis of ZnO nanowires by thermal decomposition of zinc acetate dihydrate. Mater. Chem. Phys. 2009, 113, 334-337. [CrossRef]

22. Naldoni, A.; D’Arienzo, M.; Altomare, M.; Marelli, M.; Scotti, R.; Morazzoni, F.; Selli, E.; Dal Santo, V. Pt and Au/TiO 2 photocatalysts for methanol reforming: Role of metal nanoparticles in tuning charge trapping properties and photoefficiency. Appl. Catal. B 2013, 130, 239-248. [CrossRef]

23. Jafari, T.; Moharreri, E.; Amin, A.S.; Miao, R.; Song, W.; Suib, S.L. Photocatalytic Water Splitting-The Untamed Dream: A Review of Recent Advances. Molecules 2016, 21, 900. [CrossRef]

24. Clarizia, L.; Spasiano, D.; Di Somma, I.; Marotta, R.; Andreozzi, R.; Dionysiou, D.D. Copper modified-TiO ${ }_{2}$ catalysts for hydrogen generation through photoreforming of organics. A short review. Int. J. Hydrogen Energy 2014, 39, 16812. [CrossRef]

25. Machín, A.; Cotto, M.; Duconge, J.; Arango, J.C.; Morant, C.; Pinilla, S.; Soto-Vázquez, L.; Resto, E.; Márquez, F. Hydrogen production via water splitting using different Au@ZnO catalysts under UV-vis irradiation. J. Photochem. Photobiol. A Chem. 2018, 353, 385-394. [CrossRef]

26. Pinilla, S.; Machín, A.; Park, S.H.; Arango, J.C.; Nicolosi, V.; Márquez, F.; Morant, C. $\mathrm{TiO}_{2}$-Based Nanomaterials for the Production of Hydrogen and the Development of Lithium-Ion Batteries. J. Phys. Chem. B 2017, 122, 972-983. [CrossRef] [PubMed]

27. Machín, A.; Arango, J.C.; Fontánez, K.; Cotto, M.; Duconge, J.; Soto-Vázquez, L.; Resto, E.; Petrescu, F.I.T.; Morant, C.; Márquez, F. Biomimetic Catalysts Based on Au@ZnO-Graphene Composites for the Generation of Hydrogen by Water Splitting. Biomimetics 2020, 5, 39. [CrossRef] [PubMed]

28. Uddin, M.J.; Cesano, F.; Chowdhury, A.R.; Trad, T.; Cravanzola, S.; Martra, G.; Lorenzo, M.; Zecchina, A.; Scarano, D. Surface Structure and Phase Composition of $\mathrm{TiO}_{2}$ P25 Particles After Thermal Treatments and HF Etching. Front. Mater. 2020, 7, 1-12. [CrossRef] 
29. Kowalska, E.; Rau, S.; Ohtani, B. Plasmonic Titania Photocatalysts Active under UV and Visible-Light Irradiation: Influence of Gold Amount, Size, and Shape. J. Nanotechnol. 2012, 2012, 1-11. [CrossRef]

30. Das, J.; Velusamy, P. Biogenic Synthesis of Antifungal Silver Nanoparticles Using Aqueous Stem Extract Banana. Nano. Biomed. Eng. 2013, 5, 34-38. [CrossRef]

31. Varadaveenkatesan, T.; Lyubchik, E.; Pai, S.; Pugazhendhi, A.; Vinayagam, R.; Selvaraj, R. Photocatalytic degradation of Rhodamine B by zinc oxide nanoparticles synthesized using the leaf extract of Cyanometra ramiflora. J. Photochem. Photobiol. B 2019, 199, 1-8. [CrossRef] [PubMed]

32. Han, E.; Vijayarangamuthu, K.; Youn, J.; Park, Y.K.; Jung, S.C.; Jeon, K.J. Degussa $\mathrm{P}_{2} 5 \mathrm{TiO}_{2}$ modified with $\mathrm{H}_{2} \mathrm{O}_{2}$ under microwave treatment to enhance photocatalytic properties. Catal. Today 2018, 303, 305-312. [CrossRef]

33. Wang, Y.; Zhang, M.; Fang, L.; Yange, H.; Zuo, Y.; Gao, J.; He, G.; Sun, Z. A Multifunctional Ag/TiO 2 /Reduced Graphene Oxide with Optimal Surface-Enhanced Raman Scattering and Photocatalysis. J. Am. Ceram. Soc. 2019, 102, 4000-4013. [CrossRef]

34. Hanaor, D.A.H.; Sorrell, C.C. Review of the anatase to rutile phase transformation. J. Mater. Sci. 2010, 46, 855-874. [CrossRef]

35. Korepanov, V.I.; Chan, S.Y.; Hsu, H.C.; Hamaguchi, H. Phonon confinement and size effect in Raman spectra of ZnO nanoparticles. Heliyon 2019, 5, 1-14. [CrossRef] [PubMed]

36. Liu, J.; Liu, Z.; Piao, C.; Li, S.; Tang, J.; Fang, D.; Zhang, Z.; Wang, J. Construction of fixed Z-scheme Ag| AgBr/Ag/TiO 2 photocatalyst composite film for malachite green degradation with simultaneous hydrogen production. J. Power Sources 2020, 469, 228430. [CrossRef]

37. Lu, L.; Wang, G.; Xiong, Z.; Hu, Z.; Liao, Y.; Wang, J.; Li, J. Enhanced photocatalytic activity under visible light by the synergistic effects of plasmonics and $\mathrm{Ti}^{3+}$-doping at the $\mathrm{Ag} / \mathrm{TiO}_{2-\mathrm{x}}$ heterojunction. Ceram. Int. 2020, 46, 10667-10677. [CrossRef]

38. Zhu, X.; Liang, X.; Wang, P.; Dai, Y.; Huang, B. Porous Ag-ZnO microspheres as efficient photocatalyst for methane and ethylene oxidation: Insight into the role of Ag particles. Appl. Surf. Sci. 2018, 456, 493-500. [CrossRef]

39. Tanaka, A.; Sakaguchi, S.; Hashimoto, K.; Kominami, H. Preparation of Au/ $\mathrm{TiO}_{2}$ exhibiting strong surface plasmon resonance effective for photoinduced hydrogen formation from organic and inorganic compounds under irradiation of visible light. Catal. Sci. Technol. 2012, 2, 907-909. [CrossRef]

40. Li, R.; Weng, Y.; Zhou, X.; Wang, X.; Mi, Y.; Chong, R.; Han, H.; Li, C. Achieving overall water splitting using titanium dioxide-based photocatalysts of different phases. Energy Environ. Sci. 2015, 8, 2377-2382. [CrossRef]

41. Xu, Y.; Mao, N.; Zhang, C.; Wang, X.; Zeng, J.; Chen, Y.; Wang, F.; Jiang, J.X. Rational design of donor- $\pi$-acceptor conjugated microporous polymers for photocatalytic hydrogen production. Appl. Catal. B 2018, 228, 1-9. [CrossRef]

42. Sachs, M.; Sprick, R.S.; Pearce, D.; Hillman, S.A.J.; Monti, A.; Guilbert, A.A.Y.; Brownbill, N.J.; Dimitrov, S.; Shi, X.; Blanv, F.; et al. Understanding structure-activity relationships in linear polymer photocatalysts for hydrogen evolution. Nat. Commun. 2018, 9, 4968. [CrossRef] [PubMed]

43. Zhang, Y.; Ram, M.K.; Stefanakos, E.K.; Goswami, D.Y. Synthesis, Characterization, and Applications of ZnO Nanowires. J. Nanomater. 2012, 2012, 1-22. [CrossRef]

44. Baruah, S.; Mahmood, M.A.; Myint, M.T.Z.; Bora, T.; Dutta, J. Enhanced visible light photocatalysis through fast crystallization of zinc oxide nanorods. Beilstein J. Nanotechnol. 2010, 1, 14-20. [CrossRef]

45. Baruah, S.; Dutta, J. Effect of seeded substrates on hydrothermally grown ZnO nanorods. J. Sol Gel Sci. Technol. 2009, 50, 456-464. [CrossRef]

46. Dosado, A.G.; Chen, W.T.; Chan, A.; Sun-Waterhouse, D.; Waterhouse, G.I.N. Novel Au/TiO 2 photocatalysts for hydrogen production in alcohol-water mixtures based on hydrogen titanate nanotube precursors. J. Catal. 2015, 330, 238-254. [CrossRef]

47. Rather, R.A.; Singh, S.; Pal, B. Visible and direct sunlight induced $\mathrm{H}_{2}$ production from water by plasmonic $\mathrm{Ag}$-TiO $\mathrm{O}_{2}$ nanorods hybrid interface. Sol. Energy Mater. Sol. Cells 2017, 160, 463-469. [CrossRef]

48. Imam, S.S.; Adnan, R.; Kaus, N.H.M. Photocatalytic degradation of ciprofloxacin in aqueous media: A short review. Toxicol. Environ. Chem. 2018, 100, 1-30. [CrossRef]

49. Soto-Vázquez, L.; Cotto, M.; Ducongé, J.; Morant, C.; Márquez, F. Synthesis and photocatalytic activity of $\mathrm{TiO}_{2}$ nanowires in the degradation of p-aminobenzoic acid: A comparative study with a commercial catalyst. J. Environ. Manag. 2016, 167, 23-28. [CrossRef]

50. Hu, X.; Hu, X.; Peng, Q.; Zhou, L.; Tan, X.; Jiang, L.; Tang, C.; Wang, H.; Liu, S.; Wang, Y.; et al. Mechanisms underlying the photocatalytic degradation pathway of ciprofloxacin with heterogeneous $\mathrm{TiO}_{2}$. Chem. Eng. J. 2020, 380, 1-11. [CrossRef] 